\title{
Jasmonic Acid Causes Short- and Long-Term Alterations to the Transcriptome and the Expression of Defense Genes in Sugarbeet Roots
}

\author{
Karen Klotz Fugate ${ }^{a, *}$ Lucilene Silva de Oliveira $^{b}$, Jocleita Perruzo Ferrareze ${ }^{c}$, Melvin D. Bolton ${ }^{a}$, \\ Edward L. Deckard ${ }^{d}$, and Fernando L. Finger ${ }^{b}$
}

aUSDA-ARS, Northern Crop Science Laboratory, 1605 Albrecht Blvd. N., Fargo, ND 58102-2765, USA

bDepartamento de Fitotecnia, Universidade Federal de Viçosa, 36571-000 Viçosa, MG, Brazil 'Instituto Federal de Santa Catarina, Campus Lages, Rua Heitor Villa Lobos, 222, São Francisco, Lages, SC, 88506-400, Brazil

${ }^{\mathrm{d} D e p a r t m e n t}$ of Plant Sciences, North Dakota State University, P.O. Box 6050, Fargo, ND 581086050

*Corresponding author: Karen Klotz Fugate USDA-ARS, Northern Crop Science Laboratory 1605 Albrecht Blvd. N. Fargo, ND 58102-2765, USA telephone: (701) 239-1356

fax: (701) 239-1349

email: karen.fugate@ars.usda.gov

E-mail addresses: $\quad$ karen.fugate@ars.usda.gov (K. Fugate) luagroufv@gmail.com (L. de Oliveira) joferrareze@yahoo.com.br (J. Ferrareze) melvin.bolton@ars.usda.gov (M. Bolton) edward.deckard@ndsu.edu (E. Deckard) ffinger@ufv.br (F. Finger) 
Fugate et al., p. 2

\section{Abstract}

Jasmonic acid (JA) induces native defense responses in plants and increases the resistance of postharvest sugarbeet roots to three common storage-rot causing organisms. To gain insight into the defense responses induced by JA in harvested sugarbeet roots, RNA was isolated from roots treated with water or $10 \mu \mathrm{M} \mathrm{JA}$ and incubated for 2 or $60 \mathrm{~d}$ post-treatment. RNA was sequenced, and sequence data was analyzed for short-term ( $2 \mathrm{~d}$ ) and long-term (60 d) effects of JA on the sugarbeet root transcriptome. A total of 283 and 326 differentially expressed unigenes were identified in JA-treated roots at 2 and $60 \mathrm{~d}$ after treatment, respectively. Of these, more than $96 \%$ were uniquely altered in expression at 2 or $60 \mathrm{~d}$, indicating that longterm JA-induced changes to the sugarbeet root transcriptome were substantially different from short-term JA-induced changes. Categorization of differentially expressed unigenes by gene ontology (GO) or Kyoto Encyclopedia of Genes and Genomes (KEGG) identifiers indicated that JA altered expression of a large number of unigenes involved in metabolism, including many unigenes encoding enzymes and unigenes that participate in secondary metabolism. In addition, 88 unigenes, or $15 \%$ of all unigenes whose expression were altered by JA, were putatively involved in plant defense. Included were unigenes for pathogenesis-related proteins, regulatory proteins, plant disease resistance proteins, secondary metabolite biosynthetic enzymes, oxidases, and plant cell wall-modifying proteins. Detailed, time-course expression analysis of $19 \mathrm{JA}$-altered defense unigenes revealed similarities in expression for three plant disease resistant $(R)$ genes and three laccase genes, indicating possible co-regulation of these genes. No relationships, however, were observed between enzyme activities and transcript levels for any of four major families of upregulated defense genes for which enzyme activities 
Fugate et al., p. 3

were determined, consistent with JA functioning as a primer, rather than an inducer, of plant defenses. Overall, this research supports JA's role as a signaling molecule for plant defense and provides evidence that a variety of defense mechanisms, including the production of antifungal and antimicrobial compounds, stimulation of antioxidant defenses, and stiffening and strengthening of cell walls, may contribute to JA-induced storage rot resistance in sugarbeet roots.

Keywords: Beta vulgaris; gene expression; postharvest; priming; RNA sequencing; storage

Abbreviations: ABST, 2,2'-azino-bis-(3-ethylbenzothiazoline-6-sulphonate); AP2/ERF, APETELA2/ethylene responsive factor; $\mathrm{C} 4 \mathrm{H}$, cinnamate 4-hydroxylase; $\mathrm{CC}, \mathrm{N}$-terminal coiledcoil; COG, clusters of orthologous groups; FC, fold change; FDR, false discovery rate; GO, gene ontology; JA, jasmonic acid; KEGG, Kyoto Encyclopedia of Genes and Genomes; MeJA, methyl jasmonate; NBS-LRR, nucleotide-binding site-leucine-rich repeat; POD, peroxidase; PR, pathogenesis-related; PVP-40, polyvinylpyrrolidone-40; R protein, plant disease resistance protein; SA, salicylic acid; SAMT, salicylic acid carboxyl methyltransferase. 
Fugate et al., p. 4

\section{Introduction}

Jasmonic acid (JA) and its derivatives, collectively termed jasmonates, are naturally occurring hormones that function as signaling compounds for the induction of native plant defense responses (Ballaré, 2011; Dar et al., 2015; Pozo et al., 2005). Synthesized in response to physical injury, herbivory, pathogen attack, and environmental stresses including drought, cold, and heat (Creelman and Mullet, 1997; Sharma and Lazmi, 2016; Wasternack, 2014), jasmonates have been found to increase plant tolerance to a variety of biotic and abiotic stresses including fungal, bacterial and viral pathogens, herbaceous and piercing-sucking insects, drought, high and low temperatures, heavy metals, and saline soils (Brossa et al., 2011; Dar et al., 2015; Haggag et al., 2010; Meir et al., 1996; Rohwer and Erwin, 2008). JA-induced tolerance to biotic and abiotic stresses has been correlated to changes in gene expression or protein concentration for pathogenesis-related proteins (e.g., chitinase, glucanase, and protease inhibitors), enzymes that detoxify reactive oxygen species (e.g., catalase, superoxide dismutase, and peroxidase), cell wall-modifying proteins (e.g., peroxidase and pectin methylesterase), and enzymes involved in the phenylpropanoid pathway and other secondary metabolite biosynthetic pathways. Therefore, jasmonates are thought to protect by promoting the synthesis of proteins and metabolites which are toxic, harmful, or anti-nutritive to insects or plant pathogens, by altering concentrations of reactive oxygen species, and by modifying cell wall properties (Cao et al., 2010; Denness et al., 2011; Ding et al., 2002; Gundlach et al., 1992; Rohwer and Erwin, 2008; Sun et al., 2013a). The combination of genes and proteins that are altered in expression by jasmonates, however, differs between plant species, plant organs, developmental stages, and 
Fugate et al., p. 5

the environmental conditions under which plants are grown (Bailey et al., 2005; Neller et al., 2016; Parra-Lobato et al., 2009; Rohwer and Erwin, 2008). The defense mechanisms induced by jasmonates, therefore, are dependent on a plant's genetics, age, development, production environment, and the structural organ under investigation.

Sugarbeet (Beta vulgaris L.) roots treated with jasmonic acid have improved resistance to the storage pathogens Botrytis cinerea, Penicillium claviforme, and Phoma betae (Fugate et al., 2012). Although susceptible to infection by these pathogens, JA-treated roots restrict the advancement of storage rot symptoms more effectively than untreated roots. The defense mechanisms responsible for this improved resistance are presently unknown. For other postharvest plant products, jasmonate-induced protection against storage rots has been linked to activity increases for enzymes involved in antioxidant defenses, including peroxidases, superoxide dismutases and catalases, and by defense-related proteins such as chitinases and glucanases (Cao et al., 2008; Haggag et al., 2010; Wang et al., 2009; Yao and Tian, 2005). However, no increases in these enzyme activities have been found in JA-treated sugarbeet roots (Ferrareze et al., 2013).

To provide insight into the mechanisms by which JA protects postharvest sugarbeet roots against storage rots, JA-induced alterations in the sugarbeet transcriptome at 2 and $60 \mathrm{~d}$ after treatment were determined. Two time points were chosen to identify both short-term and long-term transcriptome changes, since JA affords both rapid and long-lasting protection to sugarbeet roots against storage rots (Fugate et al., 2012). From these transcriptome changes, short- and long-term JA-induced defense genes were identified. A subset of these defense genes, chosen for high levels of expression, large induction by JA, and their putative functions, 
Fugate et al., p. 6

were characterized for temporal changes in expression and enzyme activity during the $60 \mathrm{~d}$ after treatment. From this research, we provide the first description of JA effects on the sugarbeet root transcriptome and identify defense genes that may contribute to storage rot resistance in postharvest roots.

\section{Materials and methods}

\subsection{Plant material and postharvest treatment}

Sugarbeet hybrid VDH66156 (SESVanderHave, Tienen, Belgium) was greenhouse grown in Sunshine Mix \#1 (Sun Gro Horticulture, Vancouver, Canada) in 15-L pots with supplemental light under a $16 \mathrm{~h}$ light/8 h dark regime. Taproots were harvested 16 - 18 weeks after planting, all leaf and petiole material was removed, and roots were gently washed to remove potting media. Roots were submerged in water or aqueous $10 \mu \mathrm{M}$ JA (Cayman Chemical, Ann Arbor, $\mathrm{MI}$, USA) for $1 \mathrm{~h}$ at room temperature, then stored at $20^{\circ} \mathrm{C}$ and $90 \%$ relative humidity for up to $60 \mathrm{~d}$ in a controlled environment chamber (Conviron, model MTR30, Winnipeg, Canada). JA was readily soluble in water. Root samples were acquired $0,1,2,3,10,30$, and $60 \mathrm{~d}$ post-treatment by collecting tissue from the main portion of the root, free of crown or tail tissue, with the epidermis and approximately $2 \mathrm{~mm}$ of subepidermal tissue excluded. Samples were flash frozen in liquid $\mathrm{N}_{2}$, lyophilized, ground to a powder, and stored at $-80^{\circ} \mathrm{C}$. Individual roots were the experimental unit with four replicates per treatment per time point. The experiment was repeated twice. 
Fugate et al., p. 7

\subsection{RNA isolation}

RNA for RNA sequencing experiment was isolated from tissue collected from water and JA-treated roots at 2 and $60 \mathrm{~d}$ after treatment. These time points were selected as representative times to evaluate short-term and long-term JA effects. RNA for qRT-PCR experiments was isolated from tissue collected from water and JA-treated roots at $0,1,2,3,10$, 30, and $60 \mathrm{~d}$ post-treatment. Both experiments (RNA sequencing and qRT-PCR experiments) used tissue collected from the same roots. Prior to RNA extraction, replicates for each time point and treatment within an experiment were pooled using an equal weight of lyophilized tissue from each root. Total RNA was extracted from 20 mg samples using an RNeasy Plant Mini Kit (Qiagen, Valencia, CA, USA) with an on-column DNase digestion. An Agilent Technologies 2100 Bioanalyzer (Pal Alto, CA, USA) was used to confirm RNA quality. Repetitions of the experiment served as replicates for RNA sequencing and qRT-PCR experiments.

\section{3. $R$ NA sequencing}

RNAs from roots treated with water or $10 \mu \mathrm{M} J A$ and stored for 2 and $60 \mathrm{~d}$ were converted to cDNAs and sequenced. cDNA library preparation and sequencing were performed by BGI Americas (Cambridge, MA, USA). cDNAs were sequenced using an Illumina, Inc. HiSeq 2000 system (San Diego, CA, USA). 
Fugate et al., p. 8

\subsection{Bioinformatics}

Raw sequence data was cleaned to remove reads with adapters, reads with $>10 \%$ unknown bases, and low quality reads. Clean reads were mapped to a sugarbeet reference transcriptome (Fugate et al., 2014) using SOAPaligner/soap2 (Li et al., 2009). Mismatches of no more than 2 bases were permitted. Differential gene expression between water and JA-treated roots at $2 \mathrm{~d}$ post-treatment and between water and JA-treated roots at $60 \mathrm{~d}$ post-treatment were determined, using RobiNA software (Lohse et al., 2012). Only unigenes with an absolute value of $\log _{2}$ (fold change) $\geq 1$ and a false discovery rate $(F D R) \leq 0.001$ were considered differentially expressed. WEGO software (Ye et al., 2006) was used for functional classification of differentially expressed genes using gene ontology (GO) identifiers. Unigenes were assigned to Kyoto Encyclopedia of Genes and Genomes (KEGG) pathways using the Search Pathway module of KEGG Mapper (Kanehisa et al., 2006).

\subsection{Quantitative real-time $P C R$ ( $q R T-P C R$ )}

cDNA was synthesized from total RNA using oligo(dT) primers, dNTPs, and SuperScript III reverse transcriptase (Invitrogen, Foster, CA, USA). Primer pairs were designed with Primer3Plus (Untergasser et al., 2007) as reported in Table 1. qRT-PCR was performed with a MJ Research PTC-200 thermal cycler (Watertown, MA, USA), equipped with a Chromo 4 detector (Bio-Rad Laboratories, Hercules, CA, USA) using Power SYBR Green PCR Master Mix (Applied Biosystems, Foster, CA, USA). Samples were denatured for 10 minutes at $95^{\circ} \mathrm{C}$ and amplified by 
Fugate et al., p. 9

40 cycles of $15 \mathrm{~s}$ at $95^{\circ} \mathrm{C}$ and $60 \mathrm{~s}$ at $60^{\circ} \mathrm{C}$. Three replicate qRT-PCR reactions were performed for each gene and the average Ct from the three replicates was used to calculate expression. Expression level changes were determined by the method of Pfaffl (2001), using $\beta$-actin (GenBank accession DQ866829) as a reference gene (Li and Smigocki, 2016). Melting curves confirmed that single products were amplified.

\subsection{Protein extraction and enzyme activity assays}

Laccase, peroxidase (POD), and cinnamate 4-hydroxylase $(\mathrm{C} 4 \mathrm{H})$ activities were determined by the methods of De Marco and Roubelakis-Angelakis (1997), Fugate et al. (2016), and $\mathrm{Bi}$ et al. (2007), respectively. Protein extracts were prepared by adding five volumes (w/v) of an extraction buffer to lyophilized tissue. Extraction buffers used were, laccase: $0.1 \mathrm{M}$ sodium acetate, $\mathrm{pH} 5.0$ and 1\% polyvinylpyrrolidone-40 (PVP-40); POD: $0.1 \mathrm{M}$ potassium phosphate buffer, $\mathrm{pH} 7.0,10 \mathrm{mM}$ sodium bisulfite, and $0.5 \mathrm{M} \mathrm{NaCl}$; $\mathrm{C} 4 \mathrm{H}: 0.1 \mathrm{M}$ potassium phosphate, $\mathrm{pH} 7.5$ and $2 \mathrm{mM}$ 2-mercaptoethanol. Suspensions of tissue and extraction buffer were sonicated for 15 minutes at $4{ }^{\circ} \mathrm{C}$, filtered over Miracloth (EMD Millipore, Billerica, MA, USA), and centrifuged at $20,000 \mathrm{~g}$ for 20 minutes at $4{ }^{\circ} \mathrm{C}$. Supernatants were used for laccase, POD and total soluble protein assays. For $\mathrm{C} 4 \mathrm{H}$ activity assays, supernatants were passed over Sephadex G-25 columns (GE Life Sciences, Uppsala, Sweden) equilibrated with 0.1 M potassium phosphate, $\mathrm{pH} 7.5$.

Enzyme activities were measured spectrophotometrically using a Shimadzu model UV1601 dual beam spectrophotometer (Kyoto, Japan). Laccase activity assays contained protein 
Fugate et al., p. 10

extract, $0.05 \mathrm{M}$ sodium acetate, $\mathrm{pH}$ 5.0, 0.03\% (w/v) 2,2'-azino-bis-(3-ethylbenzothiazoline-6sulphonate) (ABST), $0.1 \mathrm{mM}$ tropolone, and $60 \mathrm{U} \mathrm{mL}^{-1}$ catalase. Activity was determined by the change in absorbance at $420 \mathrm{~nm}$ after incubation at $25^{\circ} \mathrm{C}$ for $0.5 \mathrm{~h}$. POD activity assays contained protein extract, $0.1 \mathrm{M}$ potassium phosphate, $\mathrm{pH} 6.5,10 \mathrm{mM}$ guaiacol, and $4 \mathrm{mM}$ hydrogen peroxide. Activity was determined at $25^{\circ} \mathrm{C}$ using the maximum change in absorbance at $470 \mathrm{~nm}$ during the first 3 minutes of the reaction and an extinction coefficient of $26.6 \mathrm{mM}^{-1}$ $\mathrm{cm}^{-1}$ (Koduri and Tien, 1995). C4H activity assays contained desalted protein extract, $50 \mathrm{mM}$ potassium phosphate, $\mathrm{pH}$ 7.5, $2 \mathrm{mM}$ 2-mercaptoethanol, $2 \mathrm{mM}$ trans-cinnamic acid, and 0.5 mM NADPH. Reactions were incubated at $37^{\circ} \mathrm{C}$ for $1 \mathrm{~h}$ and terminated by lowering the $\mathrm{pH}$ to 1.0 with $6 \mathrm{~N} \mathrm{HCl}$. Absorbance at $340 \mathrm{~nm}$ was measured after adjusting the $\mathrm{pH}$ to 11 with $6 \mathrm{~N}$ $\mathrm{NaOH}$, and activity was determined by the change in absorbance relative to controls that lacked trans-cinnamic acid using a $p$-coumaric acid standard curve. Total soluble protein concentrations were determined using Bio-Rad Protein Assay Reagent with bovine serum albumin as a standard.

\section{Results}

\subsection{Differential expression of sugarbeet root unigenes}

Postharvest treatment with $10 \mu \mathrm{M}$ JA caused both short-term and long-term alterations to the sugarbeet root transcriptome. The cDNA libraries generated from water and JA-treated roots at 2 and $60 \mathrm{~d}$ after treatment contained an average of 72,955 expressed unigenes per 
Fugate et al., p. 11

library and ranged from 72,150 to 73,647 unigenes per library. From these libraries, 283 differentially expressed unigenes were identified in JA-treated roots $2 \mathrm{~d}$ after treatment, and 326 differentially expressed unigenes were identified in JA-treated roots $60 \mathrm{~d}$ after treatment (Table 2). Of the differentially expressed unigenes, approximately $65 \%$ were up-regulated and 35\% were down-regulated by JA at both 2 and 60 d. From a BLASTx search against GenBank nr, Swiss-Prot, COG, and KEGG protein databases (Fugate et al., 2014), 139 (49\%) of the differentially expressed unigenes $2 \mathrm{~d}$ after JA treatment and 178 (54\%) of the differentially expressed unigenes $60 \mathrm{~d}$ after treatment were annotated. Most annotations indicated putative functions for unigenes. However, approximately $14 \%$ of unigene annotations at both time points were to proteins of unknown function.

Transcriptome changes occurring $2 \mathrm{~d}$ after treatment were generally different from those occurring at $60 \mathrm{~d}$ (Fig. 1). Greater than $96 \%$ of differentially expressed unigenes were uniquely altered in expression at $2 \mathrm{~d}$ or $60 \mathrm{~d}$ after JA treatment, with only 9 unigenes upregulated and 12 unigenes down-regulated at both time points. The dissimilarity in differentially expressed unigenes for JA-treated roots at 2 and $60 \mathrm{~d}$ indicates that long-term JA effects were substantially different from short-term effects and were not merely a continuation of early JA-induced changes.

The magnitude of JA-induced gene expression changes varied from a logarithm (base 2) of the fold change in expression or $\log (\mathrm{FC})$ of -13 to +11 (Fig. 2), equivalent to expression changes of 0.0001 to 2050 -fold. The majority of differentially expressed genes were moderately altered in expression; nearly $80 \%$ of differentially expressed unigenes had log (FC) values of -5 
Fugate et al., p. 12

to +5 . Differentially expressed unigenes at $2 \mathrm{~d}$ and $60 \mathrm{~d}$ after JA treatment, with annotations and expression level changes, are available (Tables 1 and 2, in Oliveira et al., in press).

\subsection{Functional classification of differentially expressed unigenes}

\subsubsection{Gene ontology classifications}

A total of 61 and 72 differentially expressed unigenes from roots 2 and $60 \mathrm{~d}$ after JA treatment, respectively, had associated gene ontology terms, and these were used to categorize unigenes by the biological process or molecular function to which they contribute or the cellular component to which they localize (Fig. 3). Among biological processes, the greatest number of GO-annotated unigenes at both 2 and $60 \mathrm{~d}$ after treatment were functionally assigned to metabolic processes (30 unigenes at $2 \mathrm{~d}$; 37 unigenes at $60 \mathrm{~d}$ ), a functional class that includes genes involved in metabolism at the organismal level. Cellular processes, comprised of genes involved in metabolism at the cellular level, was the second most populated category within biological processes at both time points ( 21 unigenes at $2 d$; 22 unigenes at 60 d). A total of 12 and 14 GO-annotated unigenes at 2 and $60 \mathrm{~d}$ after JA treatment were categorized into the response to stimulus classification. This classification contains genes that function in the detection of and response to internal and external stimuli and includes genes involved in plant response to chemicals, hormones, and biotic and abiotic stresses.

Among molecular functions, 62 and $64 \%$ of GO-annotated unigenes, 2 and $60 \mathrm{~d}$ after JA treatment, respectively, were categorized as having catalytic activity, indicating a large portion 
of GO-annotated unigenes were putatively enzymes. Many of these unigenes were also categorized as having binding activity, and 56 and $65 \%$ of GO annotated unigenes, 2 and $60 \mathrm{~d}$ after JA treatment, respectively, were categorized as having binding activity, a classification that includes genes with regulatory functions as well as some enzymes. Jasmonate treatment is often associated with increases in antioxidant defenses (Jung, 2004; Salimi et al., 2016; SasakiSekimoto et al., 2005). However, only four differentially expressed, GO-annotated unigenes at both 2 and $60 \mathrm{~d}$ after JA treatment were classified as having antioxidant activity. Among cellular components, a large number of unigenes were unsurprisingly assigned to the cell (41 unigenes at $2 \mathrm{~d} ; 32$ unigenes at $60 \mathrm{~d}$ ) or cell part (41 unigenes at $2 \mathrm{~d} ; 32$ unigenes at $60 \mathrm{~d}$ ).

\subsubsection{Kyoto Encyclopedia of Genes and Genomes pathway mapping}

A total of 67 and 86 differentially expressed unigenes from roots at 2 and $60 \mathrm{~d}$ after JA treatment, respectively, had associated Kyoto Encyclopedia of Genes and Genomes identifiers. These identifiers were used to map differentially expressed unigenes to KEGG pathways. Differentially expressed unigenes in roots $2 \mathrm{~d}$ after JA treatment mapped to 41 KEGG pathways (Table 3). Differentially expressed unigenes in roots $60 \mathrm{~d}$ after JA treatment were more diverse and mapped to 50 KEGG pathways (Table 4). At both 2 and $60 \mathrm{~d}$ after JA treatment, $28 \%$ of the KEGG-annotated, differentially expressed unigenes were functionally assigned to metabolic pathways, a broad classification that includes enzymes involved in primary and secondary metabolism. In roots 2 and $60 \mathrm{~d}$ after JA treatment, 18 and 37\% of KEGG-annotated, 
Fugate et al., p. 14

differentially expressed unigenes, respectively, were assigned to the biosynthesis of secondary metabolites.

Differentially expressed unigenes mapped to several metabolic pathways involved in plant defense. In general, more differentially expressed unigenes from roots $60 \mathrm{~d}$ after JA treatment mapped to putative defense-related pathways than unigenes from roots $2 \mathrm{~d}$ after JA treatment. Putative defense-related pathways to which more than a single unigene mapped included plant-pathogen interaction ( 8 unigenes at $2 \mathrm{~d}$; 7 unigenes at $60 \mathrm{~d}$ ), phenylpropanoid biosynthesis ( 5 unigenes at 2 d; 9 unigenes at 60 d), phenylalanine metabolism ( 4 unigenes at 2 d; 9 unigenes at $60 \mathrm{~d}$ ), flavonoid biosynthesis ( 1 unigenes at $2 \mathrm{~d} ; 10$ unigenes at $60 \mathrm{~d}$ ), stilbenoid, diarylheptanoid and gingerol biosynthesis ( 1 unigenes at $2 \mathrm{~d}$; 8 unigenes at $60 \mathrm{~d}$ ), ubiquinone and other terpenoid-quinone biosynthesis ( 2 unigenes at $2 \mathrm{~d}$; 4 unigenes at $60 \mathrm{~d}$ ), glutathione metabolism ( 4 unigenes at $60 \mathrm{~d}$ ), flavone and flavonol biosynthesis ( 3 unigenes at $60 \mathrm{~d}$ ), and terpenoid backbone biosynthesis ( 3 unigenes at $60 \mathrm{~d}$ ).

\subsubsection{Putative defense-related unigenes}

Using annotations, GO classifications, and KEGG pathway mapping, differentially expressed unigenes with putative roles in plant defense were identified. From the differentially expressed unigenes $2 \mathrm{~d}$ post-treatment, 30 up-regulated and 8 down-regulated putative defense unigenes were identified (Table 5), while at $60 \mathrm{~d}$ post-treatment, 49 up-regulated and 4 down-regulated putative defense unigenes were found (Table 6). Of these putative defense unigenes, only three were differentially expressed at both time points: an up-regulated unigene 
Fugate et al., p. 15

with homology to cinnamate 4-hydroxylase (unigene 30677), a down-regulated unigene with homology to a gene for an Arabidopsis thaliana DNA binding protein (unigene 22684), and a down-regulated unigene (unigene 77351) with homology to Citrus trifoliate CTV.20, a gene involved in plant response to the Citrus tristeza virus (CTV).

At least $25 \%$ of unigenes with putative defense roles had annotations indicating involvement in secondary metabolite biosynthesis ( 6 unigenes at $2 d ; 17$ unigenes at $60 \mathrm{~d}$ ). Another $24 \%$ of defense-related unigenes encoded putative regulatory proteins ( 9 unigenes at 2d; 12 unigenes at $60 \mathrm{~d}$ ). These putative regulatory proteins included nucleotide-binding siteleucine-rich repeat (NBS-LRR) and N-terminal coiled-coil (CC) NBS-LRR family proteins which encode plant disease resistance $(R)$ proteins, NAC domain proteins, WRKY transcription factors, ribosome-inactivating proteins, leucine-rich repeat proteins, protein kinase family proteins, and an APETELA2/ethylene responsive factor (AP2/ERF) domain-containing transcription factor. Unigenes that encode pathogenesis-related (PR) proteins accounted for $17 \%$ of differentially expressed, defense-related unigenes and were more prevalent at $60 \mathrm{~d}$ than at $2 \mathrm{~d}$ posttreatment ( 3 unigenes at $2 d ; 12$ unigenes at $60 \mathrm{~d}$ ). Unigenes with putative PR functions encoded thaumatin-like proteins ( 3 unigenes), chitinases ( 6 unigenes), $\beta$-1,3-glucanases ( 2 unigenes), a proteinase inhibitor (1 unigene), a PR-10a protein (1 unigene), an oxalate oxidaselike germin (1 unigene), and a PR protein of unknown function (1 unigene). Differentially expressed unigenes annotated as having oxidase activity were also common in roots at both 2 and $60 \mathrm{~d}$ after JA treatment and comprised $15 \%$ of the unigenes with putative defense-related functions (9 unigenes at $2 \mathrm{~d} ; 4$ unigenes at $60 \mathrm{~d}$ ). Seven laccase and two peroxidase annotated unigenes were up-regulated in roots $2 \mathrm{~d}$ after JA treatment; three peroxidase and one oxalate 
Fugate et al., p. 16

oxidase annotated unigenes were up-regulated in roots $60 \mathrm{~d}$ after JA treatment. Five percent of differentially expressed defense-related unigenes were involved in cell wall modifications (1 unigene at $2 \mathrm{~d} ; 3$ unigenes at $60 \mathrm{~d}$ ). These unigenes were annotated as encoding three pectinesterases and one glycine-rich protein.

\subsection{Temporal expression of prominent defense unigenes using $q R T-P C R$}

Changes in gene expression during the $60 \mathrm{~d}$ post-JA incubation period were determined for 19 of the upregulated defense-related unigenes identified by RNA sequencing (Tables 5 and 6). Unigenes were selected based on their level of expression, extent of induction by JA, and putative function. Since unigenes are sequence assemblies that are typically a portion of a full length gene, some unigenes mapped to the same gene, and the 19 selected unigenes were homologous to 12 unique genes. Encoded by these 12 genes, were three plant disease R proteins, three putative PR proteins, two enzymes with prominent roles in secondary metabolism, and four oxidase enzymes.

Unigenes 9115, 10601 and 77250, and 29351, which were annotated as CC-NBS-LRR or NBS-LRR proteins, were generally upregulated in the $60 \mathrm{~d}$ after JA treatment (Fig. 4A-C). Encoding putative plant disease R proteins that are involved in pathogen detection (Belkhadir et al., 2004; DeYoung and Innes, 2006), the three genes for CC-NBS-LRR and NBS-LRR proteins were most highly expressed $2 \mathrm{~d}$ after JA treatment. Elevated expression continued for $60 \mathrm{~d}$ for genes encoding the CC-NBS-LRR resistance protein and NBS-LRR resistance protein 2 and continued for $30 \mathrm{~d}$ for the gene encoding NBS-LRR resistance protein 1. 
Fugate et al., p. 17

Expression profiles of three putative pathogenesis-related genes revealed few similarities in the effect of JA on their expression (Fig. 4D-F). A putative PR thaumatin-family protein, encoded by unigene 81205, was transiently elevated in expression 2 and $3 \mathrm{~d}$ after JA treatment and was relatively unchanged in expression $1,10,30$, and $60 \mathrm{~d}$ post-treatment. An acidic chitinase, encoded by unigene 71046, was upregulated 2 and $60 \mathrm{~d}$ after JA treatment and was unaltered in expression at all other time points. Another chitinase, acidic chitinase SE2, encoded by unigenes 53522, 66160 and 70896, was down-regulated $1 \mathrm{~d}$ after JA treatment, unaltered in expression 2 to $30 \mathrm{~d}$ post-treatment, and significantly upregulated $60 \mathrm{~d}$ posttreatment.

Four JA-induced oxidases, including three laccase genes and one peroxidase gene, shared similarities in their expression profiles (Fig. 5A-D). All four oxidase genes were maximally upregulated in the first $3 \mathrm{~d}$ after JA treatment. The peroxidase encoded by unigenes 42562 and 66692 was most highly upregulated $2 \mathrm{~d}$ after JA treatment; the three laccase genes, encoded by unigenes 11281 (laccase 1), 51666, 67039 and 68954 (laccase 2), and 78937 (laccase 3), were most highly upregulated $3 \mathrm{~d}$ after treatment. For all four oxidases, up-regulation by JA ceased by $10 \mathrm{~d}$. No significant induction of any of the oxidases was observed with continued incubation time, except for transient increases in laccase 1 expression at $60 \mathrm{~d}$ post-treatment and laccase 3 expression at $30 \mathrm{~d}$ post-treatment.

Cinnamate 4-hydroxylase $(\mathrm{C} 4 \mathrm{H})$ catalyzes the conversion of trans-cinnamic acid to $p$ coumaric acid, a key reaction in the early steps of the phenylpropanoid pathway which leads to the production of lignins, flavonoids, coumarins, isoflavonoids, and a variety of other plant defense compounds (Lu et al., 2006). The JA-induced C4H gene identified by RNA sequencing 
Fugate et al., p. 18

(unigenes 30677 and 55958) was up-regulated 2, 3 and $60 \mathrm{~d}$ after JA treatment with maximal up-regulation at $60 \mathrm{~d}$ (Fig. 5E). Salicylic acid carboxyl methyltransferase (SAMT) catalyzes the methylation of salicylic acid (SA) to methyl salicylate to create a volatile SA metabolite that can decrease endogenous SA levels and serve as an airborne signal to prime SA-induced defenses in adjacent plants (Koo et al. 2007; Shulaev et al., 1997). The JA-induced SAMT gene identified by RNA sequencing (unigene 29506) was down-regulated $1 \mathrm{~d}$ after JA treatment, but was upregulated 2-60 d post-treatment, with maximal expression observed 2-3 d after treatment (Fig. $5 F)$.

\subsection{Enzyme activities for JA-induced defense genes}

Enzymatic activities of laccase, peroxidase, chitinase, and cinnamate 4-hydroxylase were determined to evaluate the extent that transcriptional changes in the genes encoding for these proteins led to changes in their activities. Despite significant increases in laccase transcripts 1-3 d after JA treatment (Fig. 5A-C), laccase activity was below the level of detection at 1, 2, 3, 10, 30, and $60 \mathrm{~d}$ post-treatment (data not shown). POD activity was measured with high saltcontaining extracts that were expected to contain both soluble and cell wall peroxidase proteins (Fry, 1988). While POD transcripts increased 2-3 d after JA treatment (Fig. 5D), POD activity was unaltered from that of water-treated controls throughout the $60 \mathrm{~d}$ after treatment

(Fig. 6A). Chitinase activity in JA-treated roots was measured previously and was unchanged at $1,2,3,10$, and $60 \mathrm{~d}$ after JA treatment and reduced $30 \mathrm{~d}$ after treatment relative to watertreated roots (Ferrareze et al., 2013). In contrast, chitinase gene expression decreased $1 \mathrm{~d}$ after 
Fugate et al., p. 19

JA treatment and increased 2 and $60 \mathrm{~d}$ after JA treatment (Fig. 4E-F). Similar to laccase, POD, and chitinase, $\mathrm{JA}$-induced changes in $\mathrm{C} 4 \mathrm{H}$ gene expression did not lead to similar changes in $\mathrm{C} 4 \mathrm{H}$ activity. $\mathrm{C} 4 \mathrm{H}$ activity was present at low and relatively unchanging levels in both $\mathrm{JA}$ and water-treated roots throughout the $60 \mathrm{~d}$ after JA treatment (Fig. 6B). However, $\mathrm{C} 4 \mathrm{H}$ expression increased 2, 3, and $60 \mathrm{~d}$ after treatment in JA-treated roots relative to water-treated controls (Fig. 5E).

\section{Discussion}

Postharvest treatment with JA induced significant short-term and long-term changes to the transcriptome of sugarbeet roots. Two days after JA treatment, 283 unigenes were identified that were altered in their expression due to JA treatment. Sixty days after treatment, 326 differentially expressed unigenes were identified. Alterations to the transcriptome during the first $7 \mathrm{~d}$ after JA or methyl jasmonate (MeJA) treatment have been reported previously for a variety of plant species (Babst et al, 2009; Gális et al, 2006; Hao et al., 2015; Oliveira et al., 2015; Ramírez-Estrada et al., 2016; Salzman et al., 2005; Sasaki-Sekimoto et al., 2005; Sun et al, 2013b). However, to our knowledge, this is the first report of a jasmonate treatment causing long-term transcriptomic changes. Nevertheless, jasmonates are responsible for long-term physiological effects on sugarbeet roots and other harvested plant organs, including improved disease resistance in sugarbeet roots and pears stored for 50 and $60 \mathrm{~d}$, respectively (Fugate et al., 2012; Zhang et al., 2009), and improved resistance to chilling injury in cherry tomato, peach and loquat fruits stored for 21, 35, and 35 d, respectively (Cai et al., 2011; Jin et al., 2009; Zhang 
Fugate et al., p. 20

et al., 2012). Long-term, JA-induced changes in the transcriptome may play a role in these longterm, jasmonate-induced physiological effects.

Fifty-four percent of JA-altered unigenes were unannotated or encoded proteins with no known function. The remaining $46 \%$ of JA-altered unigenes were annotated and were predominantly involved in plant metabolism. When JA-altered unigenes were classified into the biological processes to which they contribute using GO terms, metabolic processes and cellular processes were the two most highly populated categories. These categories contain genes that are involved in plant metabolism at the organismal and cellular level. Classification of JA-altered unigenes by molecular function based on GO annotations demonstrated a predominance of unigenes with catalytic and binding functions, indicating that JA affected the expression of numerous enzymes and regulatory proteins. KEGG pathway analysis similarly indicated a preponderance of JA-altered unigenes involved in metabolism, especially secondary metabolism, as a large number of unigenes mapped to metabolic pathways, a category that includes enzymes involved in primary and secondary metabolism, and to the biosynthesis of secondary metabolites pathway. Large changes in the transcriptome due to exogenous JA or MeJA treatment have been previously reported for a number of plant species (Babst et al, 2009; Gális et al, 2006; Hao et al., 2015; Lee and Choi, 2013; Oliveira et al., 2015; RamírezEstrada et al., 2016; Salzman et al., 2005; Sasaki-Sekimoto et al., 2005; Sun et al, 2013b; Zang et al., 2015). As in sugarbeet root, cellular and molecular processes, and binding and catalytic functions typically dominate GO classifications, and metabolic pathways and biosynthesis of secondary metabolites generally predominate as the KEGG pathways to which JA-altered genes map (Oliveira et al., 2015; Zang et al., 2015). 
Fugate et al., p. 21

JA treatment of sugarbeet roots altered the expression of many unigenes involved in plant defense. A total of 88 unigenes, or $15 \%$ of all JA-altered unigenes, were assigned putative roles in plant defense, including unigenes that encoded pathogenesis-related proteins, plant disease resistance proteins, enzymes involved in secondary metabolite biosynthesis, oxidases, and plant cell wall-modifying proteins. The variety of JA-induced defense genes in sugarbeet indicates $\mathrm{JA}^{\prime}$ 's potential to protect roots by multiple mechanisms including production of antifungal and antimicrobial compounds, stimulation of antioxidant defenses, and stiffening and strengthening of cell walls. Elevated expression of genes encoding PR proteins, and enzymes involved in secondary metabolite biosynthesis in response to jasmonate elicitation is common in plants, and reports of JA or MeJA inducing genes for oxidases, cell wall modifying enzymes, and R proteins can be found (Bailey et al., 2005; Ding et al., 2002; Gális et al, 2006; Hao et al., 2015; Oliveira et al., 2015; Salzman et al., 2005; Sun et al., 2013b; Zang et al., 2015). The collection of defense genes induced by a postharvest JA treatment, however, was unique to sugarbeet roots.

JA induced a number of defense-related regulatory proteins, including an APETELA2/ethylene responsive factor (AP2/ERF) domain-containing transcription factor and a gene for salicylic acid carboxyl methyltransferase (SAMT), an enzyme that regulates active SA concentrations and is involved in plant-to-plant SA signaling (Koo et al., 2007; Shulaev et al., 1997). Upregulation of regulatory genes was expected because of JA's well-established role as a signaling compound for plant defenses (Ballaré, 2011; Wasternack and Hause, 2013), while alteration of AP2/ERF and SAMT expression suggests interactions between JA, ethylene, and SA-regulated pathways in sugarbeet root. Cross-talk between jasmonates, ethylene, and 
salicylate in the elicitation of plant defenses has been reported in other plant species (Koornneef and Pieterse, 2008; Thaler et al., 2012).

Long-term changes in the sugarbeet transcriptome due to JA treatment were distinctly different from short-term changes. Of the 578 unigenes that were altered in expression, only 21 unigenes, or $3.6 \%$ of all unigenes, were commonly altered in expression at both 2 and $60 \mathrm{~d}$. Long-term effects of JA on the sugarbeet root transcriptome, therefore, were not a prolongation of transcriptome changes from $2 \mathrm{~d}$. In general, differentially expressed unigenes were more diverse at $60 \mathrm{~d}$ than at $2 \mathrm{~d}$, as JA-altered unigenes mapped to $22 \%$ more KEGG pathways at $60 \mathrm{~d}$ after treatment than at $2 \mathrm{~d}$ after treatment. Additionally, upregulated defense unigenes were more abundant at $60 \mathrm{~d}$ post-treatment, and approximately $60 \%$ more differentially expressed defense unigenes were identified at $60 \mathrm{~d}$ than at $2 \mathrm{~d}$. Unigenes that encode PR proteins and enzymes involved in the biosynthesis of secondary metabolites were induced by JA at both 2 and $60 \mathrm{~d}$ after treatment. However, unigenes for PR proteins were 3fold more abundant at $60 \mathrm{~d}$ and unigenes that participate in secondary metabolite biosynthesis were nearly 2 -fold more abundant at $60 \mathrm{~d}$. In contrast, unigenes encoding oxidases, especially those for laccases, were more numerous at $2 \mathrm{~d}$ after JA treatment than at $60 \mathrm{~d}$. Differentially expressed unigenes for regulatory proteins were approximately evenly distributed between 2 and 60 days post-treatment. However, plant disease resistance proteins were more abundant at $2 \mathrm{~d}$ after JA treatment, and WRKY transcription factors, which have been identified as key regulators of plant defense responses to biotic and abiotic stresses (Chen et al., 2012; Pandey and Somssich, 2009), were differentially expressed only at $60 \mathrm{~d}$. 
Fugate et al., p. 23

Determination of changes in expression for a number of defense-related genes

throughout the $60 \mathrm{~d}$ storage period revealed similarities in expression for some defense genes.

Most notable were similarities in expression for three putative $\mathrm{R}$ protein-encoding genes and three laccase genes. Three genes for R proteins, i.e., CC-NBS-LRR resistance protein, NBS-LRR resistance protein 1, and NBS-LRR resistance protein 2, all exhibited the greatest induction $2 \mathrm{~d}$ after JA treatment and were generally up-regulated throughout the $60 \mathrm{~d}$ after JA treatment. The three laccase genes, i.e., laccase 1, laccase 2, and laccase 3, were upregulated 2 and $3 \mathrm{~d}$ after JA treatment, exhibited the greatest upregulation at $3 \mathrm{~d}$ post-treatment, and were no longer upregulated by $10 \mathrm{~d}$ post-treatment. Similarities in expression among sugarbeet root defense genes may be coincidental. However, similarities in expression have often been interpreted as signs of co-regulation of genes (Gachon et al., 2005; Yu et al., 2003). In contrast, no similarities in expression were noted for the PR-protein encoding genes for which timecourses were generated, suggesting there was no co-regulation of these genes.

Determination of enzyme activities for four major families of upregulated defense genes indicated that JA-induced alterations in gene expression did not cause similar alterations in protein activity. RNA sequencing identified five laccase genes, five peroxidase genes, three chitinase genes, and one cinnamate 4-hydroxylase gene that were upregulated 2 or $60 \mathrm{~d}$ after JA treatment. However, in the $60 \mathrm{~d}$ following JA treatment, laccase activity was undetectable, peroxidase and chitinase activities were not elevated over activities of untreated roots, and $\mathrm{C} 4 \mathrm{H}$ exhibited minor fluctuations in activity that bore no relationship to changes in $\mathrm{C} 4 \mathrm{H}$ gene expression. The discrepancy between gene expression and enzyme activity suggests that JA probably functions as a primer, rather than an inducer, of plant defenses for these four families 
Fugate et al., p. 24

of genes (Conrath et al., 2002). As a primer, JA does not directly induce plant defense responses, but alters the plant's molecular machinery to allow for a more rapid and vigorous induction of defenses upon subsequent challenge with a biotic or abiotic stress (Conrath, 2011). Elevation in transcript levels for defense-related genes, as occurred for laccase, peroxidase, chitinase and $\mathrm{C} 4 \mathrm{H}$ genes in JA-treated sugarbeet root, is documented as a priming mechanism for plant defense responses (Christou et al., 2013; 2014; Savvides et al., 2016).

Postharvest JA treatment of sugarbeet roots restricts the progression of storage rot caused by B. cinerea, P. claviforme, and P. betae (Fugate et al., 2012). Concurrent with that protection, we report here that JA causes major changes to the sugarbeet root transcriptome and alters the expression of many genes with putative roles in plant defense. The mechanisms by which JA protects postharvest sugarbeet roots against storage rots remains to be established. However, upregulation of genes for PR proteins, enzymes involved in the biosynthesis of secondary metabolites, oxidases, and cell wall-modifying proteins, suggests that JA affords protection by stimulating production of antifungal and antimicrobial compounds, inducing antioxidant defenses, and by stiffening and strengthening cell walls. Upregulation of genes for regulatory proteins, including plant disease resistance genes and genes involved in ethylene and SA signaling and metabolism, indicate that JA potentially protects sugarbeet roots by promoting their ability to recognize and respond to plant pathogens and through interaction with ethylene and SA-induced defense-related pathways. The protection afforded by JA to postharvest sugarbeet roots occurs quickly, is durable for at least $50 \mathrm{~d}$ (Fugate et al., 2012), and coincided with both short-term and long-term changes in gene expression. Long-term transcriptome changes, however, were distinctly different from short-term transcriptome 
Fugate et al., p. 25

changes, suggesting that the protection afforded by JA shortly after treatment differs from the protection provided months later. Additionally, evidence presented here suggests that JA acts as a primer, rather than an inducer, of plant defenses in sugarbeet root, as changes in gene expression did not result in similar changes in enzyme activity.

\section{Acknowledgements}

The authors thank John Eide for technical assistance, CNPq (Brazil) for scholarships provided to L.S.O. and J.P.F, and the Beet Sugar Development Foundation for partial financial support of this research. Mention of trade names or commercial products is solely for the purpose of providing specific information and does not imply recommendation or endorsement by the U.S. Department of Agriculture. USDA is an equal opportunity provider and employer. 


\section{References}

Babst, B.A., Sjödin, A., Jansson, S., Orians, C.M., 2009. Local and systemic transcriptome responses to herbivory and jasmonic acid in Populus. Tree Genet. Genomes 5, 459-474.

Bailey, B.A., Strem, M.D., Bae, H., de Mayolo, G.A., Guiltinan, M.J., 2005. Gene expression in leaves of Theobroma cacao in response to mechanical wounding, ethylene, and/or methyl jasmonate. Plant Sci. 168, 1247-1258.

Ballaré, C.L., 2011. Jasmonate-induced defenses: a tale of intelligence, collaborators and rascals. Trends Plant Sci. 16, 249-257.

Belkhadir, Y., Subramaniam, R., Dangl, J.L., 2004. Plant disease resistance protein signaling: NBS-LRR proteins and their partners. Curr. Opin. Plant Biol. 7, 391-399.

Bi, H.H., Zeng, R.S., Su, L.M., An, M., Luo, S.M., 2007. Rice allelopathy induced by methyl jasmonate and methyl salicylate. J. Chem. Ecol. 33, 1089-1103.

Brossa, R., López-Carbonell, M., Jubany-Marí, T., Alegre, L., 2011. Interplay between abscisic acid and jasmonic acid and its role in water-oxidative stress in wild-type, ABA-deficient, JAdeficient, and ascorbate-deficient Arabidopsis plants. J. Plant Growth Regul. 30, 322-333.

Cai, Y., Cao, S., Yang, Z., Zheng, Y., 2011. MeJA regulates enzymes involved in ascorbic acid and glutathione metabolism and improves chilling tolerance in loquat fruit. Postharvest Biol. Technol. 59, 324-326.

Cao, S., Zheng, Y., Wang, K., Rui, H., Tang, S., 2010. Effect of methyl jasmonate on cell wall modification of loquat fruit in relation to chilling injury after harvest. Food Chem. 118, 641647. 
Cao, S., Zheng, Y., Yang, Z., Tang, S., Jin, P., Wang, K., Wang, X., 2008. Effect of methyl jasmonate on the inhibition of Colletotrichum acutatum infection in loquat fruit and the possible mechanisms. Postharvest Biol. Technol. 49, 301-307.

Chen, L., Song, Y., Li, S., Zhang, L., Zou, C., Yu, D., 2012. The role of WRKY transcription factors in plant abiotic stresses. Biochim. Biophys. Acta 1819, 120-128.

Christou, A., Filippou, P., Manganaris, G.A., Fotopoulos, V., 2014. Sodium hydrosulfide induces systemic thermotolerance to strawberry plants through transcriptional regulation of heat shock proteins and aquaporin. BMC Plant Biol. 14, 42.

Christou, A., Manganaris, G.A., Papadopoulos, I., Fotopoulos, V., 2013. Hydrogen sulfide induces systemic tolerance to salinity and non-ionic osmotic stress in strawberry plants through modification of reactive species biosynthesis and transcriptional regulation of multiple defence pathways. J. Exp. Bot. 64, 1953-1966.

Conrath, U., 2011. Molecular aspects of defence priming. Trends Plant Sci. 16, 524-531.

Conrath, U., Pieterse, C.M.J., Mauch-Mani, B., 2002. Priming in plant-pathogen interactions. Trends Plant Sci. 7, 210-216.

Creelman, R.A., Mullet, J.E., 1997. Biosynthesis and action of jasmonate in plants. Annu. Rev. Plant Physiol. Plant Mol. Biol. 48, 355-381.

Dar, T.A., Uddin, M., Khan, M.M.A., Hakeem, K.R., Jaleel, H., 2015. Jasmonates counter plant stress: a review. Environ. Exp. Bot. 115, 49-57.

DeMarco, A., Roubelakis-Angelakis, K.A., 1997. Laccase activity could contribute to cell-wall reconstitution in regenerating protoplasts. Phytochemistry 46, 421-425. 
Denness, L., McKenna, J.F., Segonzac, C., Wormit, A., Madhou, P., Bennett, M., Mansfield, J., Zipfel, C., Hamann, T., 2011. Cell wall damage-induced lignin biosynthesis is regulated by a reactive oxygen species- and jasmonic acid-dependent process in Arabidopsis. Plant Physiol. 156, 1364-1374.

DeYoung, B.J., Innes, R.W., 2006. Plant NBS-LRR proteins in pathogen sensing and host defense. Nat. Immunol. 7, 1243-1249.

Ding, C.-K., Wang, C., Gross, K.C., Smith, D.L., 2002. Jasmonate and salicylate induce the expression of pathogenesis-related-protein genes and increase resistance to chilling injury in tomato fruit. Planta 214, 895-901.

Dohm, J.C., Minoche, A.E., Holtgräwe, D., Capella-Gutiérrez, S., Zakrzewski, F., Tafer, H., Rupp, O., Sörensen, T.R., Stracke, R., Reinhardt, R., Goesmann, T., Kraft, T., Schulz, B., Stadler, P.F., Schmidt, T., Gabaldón, T., Lehrach, H., Weisshaar, B., Himmelbauer, H., 2014. The genome of the recently domesticated crop plant sugar beet (Beta vulgaris). Nature 505, 546-549.

Ferrareze, J.P., Fugate, K.K., Bolton, M.D., Deckard, E.L., Campbell, L.G., Finger, F.L., 2013. Jasmonic acid does not increase oxidative defense mechanisms or common defenserelated enzymes in postharvest sugarbeet roots. Postharvest Biol. Technol. 77, 11-18.

Fry, S.C., 1988. The growing plant cell wall: chemical and metabolic analysis. Longman, London. Fugate, K., 2013. Sugarbeet transcriptome unigenes. figshare. http://figshare.com/articles/Sugarbeet_transcriptome_unigenes/843615 (accessed 19 Oct 2016). 
Fugate, K.K., Fajardo, D., Schlautman, B., Ferrareze, J.P., Bolton, M.D., Campbell, L.G., Wiesman, E., Zalapa, J., 2014. Generation and characterization of a sugarbeet transcriptome and transcript-based SSR markers. Plant Genome 7, 1-13.

Fugate, K.K., Ferrareze, J.P., Bolton, M.D., Deckard, E.L., Campbell, L.G., 2012. Postharvest jasmonic acid treatment of sugarbeet roots reduces rot due to Botrytis cinerea, Penicillium claviforme, and Phoma betae. Postharvest Biol. Technol. 65, 1-4.

Fugate, K.K., Ribeiro, W.S., Lulai, E.C., Deckard, E.L., Finger, F.L., 2016. Cold temperature delays wound healing in postharvest sugarbeet roots. Frontiers Plant Sci. 7, article 499.

Gachon, C.M.M., Langlois-Meurinne, M., Henry, Y., Saindrenan, P., 2005. Transcriptional coregulation of secondary metabolism enzymes in Arabidopsis: functional and evolutionary implications. Plant Mol. Biol. 58, 229-245.

Gális, I., Ŝimek, P., Narisawa, T., Sasaki, M., Horiguchi, T., Fukuda, H., Matsuoka, K., 2006. A novel R2R3 MYB transcription factor NtMYBJS1 is a methyl jasmonate-dependent regulator of phenylpropanoid-conjugate biosynthesis in tobacco. Plant J. 46, 573-592.

Gundlach, H., Müller, M.J., Kutchan, T.M., Zenk, M.H., 1992. Jasmonic acid is a signal transducer in elicitor-induced plant cell cultures. Proc. Natl. Acad. Sci. USA 89, 2389-2393.

Haggag, W.M., Mahmoud, Y.S., Farag, E.M., 2010. Signaling necessities and function of polyamines/jasmonate-dependent induced resistance in sugar beet against beet mosaic virus (BtMV) infection. New York Sci. J. 3, 95-103.

Hao, D.C., Chen, S.L., Osbourn, A., Kontogianni, V.G., Liu, L.W., Jordán, M.J., 2015. Temporal transcriptome changes induced by methyl jasmonate in Salvia sclarea. Gene 558, 41-53. 
Holstege, F.C.P., Jennings, E.G., Wyrick, J.J., Lee, T.I., Hengartner, C.J., Green, M.R., Golub, T.R., Lander, E.S., Young, R.A., 1998. Dissecting the regulatory circuitry of a eukaryotic genome. Cell 95, 717-728.

Jin, P., Zheng, Y., Tang, S., Rui, H., Wang, C.Y., 2009. A combination of hot air and methyl jasmonate vapor treatment alleviates chilling injury of peach fruit. Postharvest Biol. Technol. 52, 24-29.

Jung, S., 2004. Effect of chlorophyll reduction in Arabidopsis thaliana by methyl jasmonate or norflurazon on antioxidant systems. Plant Physiol. Biochem. 42, 225-231.

Kanehisa, M., Goto, S., Hattori, M., Aoki-Kinoshita, K.F., Itoh, M., Kawashima, S., Katayama, T., Araki, M., Hirakawa, M., 2006. From genomics to chemical genomics: new developments in KEGG. Nucleic Acids Res. 34 (Database issue), D354-D357.

Koduri, R.S., Tien, M., 1995. Oxidation of guaiacol by lignin peroxidase. J. Biol. Chem. 270, 22254-22258.

Koo, Y.J., Kim, M.A., Kim, E.H., Song, J.T., Jung, C., Moon, J.K., Kim, J.H., Seo, H.S., Song, S.I., Kim, J.K., Lee, J.S., Cheong, J.J., Choi, Y.D., 2007. Overexpression of salicylic acid carboxyl methyltransferase reduces salicylic acid-mediated pathogen resistance in Arabidopsis thaliana. Plant Mol. Biol. 64, 1-15.

Koornneef, A., Pieterse, C.M.J., 2008. Cross talk in defense signaling. Plant Physiol. 146, 839844.

Lee, S., Choi, D., 2013. Comparative transcriptome analysis of pepper (Capsicum annuum) revealed common regulons in multiple stress conditions and hormone treatments. Plant Cell Rep. 32, 1351-1359. 
Li, H., Smigocki, A.C., 2016. Wound induced Beta vulgaris polygalacturonase-inhibiting protein genes encode a longer leucine-rich repeat domain and inhibit fungal polygalacturonases. Physiol. Mol. Plant Pathol. 96, 8-18.

Li, R., Zhu, H., Ruan, J., Qian, W., Fang, X., Shi, Z., Li, Y., Li, S., Shan, G., Kristiansen, K., Li, S., Yang, H., Wang, J., Wang. J., 2009. De novo assembly of human genomes with massively parallel short read sequencing. Genome Res. 20, 265-272.

Lohse, N., Bolger, A.M., Nagel, A., Fernie, A.R., Lunn, J.E., Stitt, M., Usadel, B., 2012. RobiNA: a user-friendly, integrated software solution for RNA-Seq-based transcriptomics. Nucleic Acids Res. 40 (Web Server issue), W622-W627.

Lu, S., Zhou, Y., Li, L., Chiang, V.L., 2006. Distinct roles of cinnamate 4-hydroxylase genes in Populus. Plant Cell Physiol. 47, 905-914.

Meir, S., Philosoph-Hadas, S., Lurie, S., Droby, S., Akerman, M., Zauberman, G., Shapiro, B., Cohen, E., Fuchs, Y., 1996. Reduction of chilling injury in stored avocado, grapefruit, and bell pepper by methyl jasmonate. Can. J. Botany $74,870-874$.

Neller, C.C.M., Klenov, A., Hudak, K.A., 2016. The pokeweed leaf mRNA transcriptome and its regulation by jasmonic acid. Front. Plant Sci., 7, article 283.

Oliveira, M.B., Junior, M.L., Grossi-de-Sá, M.F., Petrofeza, S., 2015. Exogenous application of methyl jasmonate induces a defense response and resistance against Sclerotinia sclerotiorum in dry bean plants. J. Plant Physiol. 182, 13-22.

Pandey, S.P., Somssich, I.E., 2009. The role of WRKY transcription factors in plant immunity. Plant Physiol. 150, 1648-1655. 
Parra-Lobato, M.C., Fernandez-Garcia, N., Olmos, E., Alvarez-Tinaut, M.C., Gómez-Jiménez, M.C., 2009. Methyl jasmonate-induced antioxidant defence in root apoplast from sunflower seedlings. Environ. Exp. Bot. 66, 9-17.

Pfaffl M.W., 2001. A new mathematical model for relative quantification in real-time RT-PCR. Nucleic Acids Res. 29, 2002-2007.

Pozo, M.J., van Loon, L.C., Pieterse, C.J., 2005. Jasmonates-signals in plant microbe interactions. J. Plant Growth Regul. 23, 211-222.

Ramírez-Estrada, K., Altabella, T., Onrubia, M., Moyano, E., Notredame, C., Osuna, L., Bossche, B.V., Goossens, A., Cusido, R.M., Palazon. J., 2016. Transcript profiling of jasmonate-elicited Taxus cells reveals a $\beta$-phenylalanine-CoA ligase. Plant Biotechnol. J. 14, 85-96.

Rohwer, C.L., Erwin, J.E., 2008. Horticultural applications of jasmonates: a review. J. Hort. Sci. Biotech. 83, 283-304.

Salimi, F., Shekari, F., Hamzei, J., 2016. Methyl jasmonate improves salinity resistance in German chamomile (Matricaria chamomilla L.) by increasing activity of antioxidant enzymes. Acta Physiol. Plant. 38, 1.

Salzman, R.A., Brady, J.A., Finlayson, S.A., Buchanan, C.D., Summer, E.J., Sun, F., Klein, P.E., Klein, R.R., Pratt, L.H., Cordonnier-Pratt, M.-M., Mullet, J.E., 2005. Transcriptional profiling of sorghum induced by methyl jasmonate, salicylic acid, and aminocyclopropane carboxylic acid reveals cooperative regulation and novel gene responses. Plant Physiol. 138, 352-368. Sasaki-Sekimoto, Y., Taki, N., Obayashi, T., Aono, M., Matsumoto, F., Sakurai, N., Suzuki, H., Hirai, M.Y., Noji, M., Saito, K., Masuda, T., Takamiya, K., Shibata, D., Ohta, H., 2005. 
Fugate et al., p. 33

Coordinated activation of metabolic pathways for antioxidants and defence compounds by jasmonates and their roles in stress tolerance in Arabidopsis. Plant J. 44, 653-668.

Savvides, A., Ali, S., Tester, M., Fotopoulos, V., 2016. Chemical priming of plants against multiple abiotic stresses: mission possible? Trends Plant Sci. 21, 329-340.

Sharma, M., Laxmi, A., 2016. Jasmonates: emerging players in controlling temperature stress tolerance. Front. Plant Sci. 6, article 1129.

Shulaev, V., Silverman, P., Raskin, I., 1997. Airborne signaling by methyl salicylate in plant pathogen resistance. Nature $385,718-721$.

Sun, D., Lu, X., Hu, Y., Li, W., Hong, K., Mo, Y., Cahill, D.M., Xie, J., 2013a. Methyl jasmonate induced defense responses increase resistance to Fusarium oxysporum f. sp. cubense race 4 in banana. Scientia Hortic. 164, 484-491.

Sun, G., Yang, Y., Xie, F., Wen, J.-F., Wu, J., Wilson, I.W., Tang, Q., Liu, H., Qiu, D., 2013b. Deep sequencing reveals transcriptome re-programming of Taxus $x$ media cells to the elicitation with methyl jasmonate. PLoS ONE 8, e62865.

Thaler, J.S., Humphrey, P.T., Whiteman, N.K., 2012. Evolution of jasmonate and salicylate signal crosstalk. Trends Plant Sci. 17, 260-270.

Untergasser, A., Nijveen, H., Rao, X., Bisseling, T., Geurts, R., Leunissen, J.A.M., 2007. Primer3Plus, an enhanced web interface to Primer3. Nucleic Acids Res. 35, W71-W74.

Wang, K., Jin, P., Cao, S., Shang, H., Yang, Z., Zheng, Y., 2009. Methyl jasmonate reduces decay and enhances antioxidant capacity in Chinese bayberries. J. Agricul. Food Chem. 57, 58095815. 
Fugate et al., p. 34

Wasternack, C., 2014. Action of jasmonates in plant stress responses and developmentapplied aspects. Biotechnol. Adv. 32, 31-39.

Wasternack, C., Hause, B., 2013. Jasmonates: biosynthesis, perception, signal transduction and action in plant stress response, growth and development. An update to the 2007 review in Annals of Botany. Ann. Bot. 111, 1021-1058.

Yao, H.J., Tian, S.P., 2005. Effects of a biocontrol agent and methyl jasmonate on postharvest diseases of peach fruit and the possible mechanisms involved. J. Appl. Microbiol. 98, 941950.

Ye, J., Fang, L., Zheng, H., Zhang, Y., Chen, J., Zhang, Z., Wang, J., Li, S., Li, R., Bolund, L., Wang, J., 2006. WEGO: a web tool for plotting GO annotations. Nucleic Acids Res. 34, 293-297.

Yu, H., Luscombe, N.M., Qian, J., Gerstein, M., 2003. Genomic analysis of gene expression relationships in transcriptional regulatory networks. Trends Genet. 19, 422-427.

Zang, Y., Zheng, W., He, Y., Hong, S.-B., Zhu, Z., 2015. Global analysis of transcriptional response of Chinese cabbage to methyl jasmonate reveals JA signaling on enhancement of secondary metabolism pathways. Sci. Hort. 189, 159-167.

Zhang, H., Ma, L., Turner, M., Xu, H. Dong, Y., Jiang, S., 2009. Methyl jasmonate enhances biocontrol efficacy of Rhodotorula glutinis to postharvest blue mold decay of pears. Food Chem. 117, 621-626.

Zhang, X., Sheng, J., Li, F., Meng, D., Shen, L., 2012. Methyl jasmonate alters arginine catabolism and improves postharvest chilling tolerance in cherry tomato fruit. Postharvest Biol. Technol. 64, 160-167. 
Fugate et al., p. 35

\section{Figure captions}

Fig. 1. Heterogeneity of differentially expressed unigenes in sugarbeet roots treated with jasmonic acid (JA) and stored for 2 or $60 \mathrm{~d}$. Venn diagrams display the diversity in (A) upregulated unigenes from roots $2 \mathrm{~d}$ and $60 \mathrm{~d}$ after JA treatment and (B) down-regulated unigenes from roots $2 \mathrm{~d}$ and $60 \mathrm{~d}$ after JA treatment. Roots were treated with $10 \mu \mathrm{M}$ JA or water following harvest and incubated at $20^{\circ} \mathrm{C}$ and $90 \%$ relative humidity for up to $60 \mathrm{~d}$. Differentially expressed unigenes between JA and water-treated roots were determined by RNA-sequencing.

Fig 2. Distribution in the magnitude of changes in gene expression for differentially expressed unigenes from sugarbeet roots 2 and $60 \mathrm{~d}$ after jasmonic acid (JA) treatment. The magnitude change in gene expression was determined as the $\log _{2}$ (fold change) in the number of RNAs sequenced from JA-treated roots relative to water-treated roots for each unigene. Roots were treated with $10 \mu \mathrm{M} \mathrm{JA}$ or water following harvest and incubated at $20{ }^{\circ} \mathrm{C}$ and $90 \%$ relative humidity for up to $60 \mathrm{~d}$.

Fig. 3. Classification of differentially expressed sugarbeet unigenes due to jasmonic acid (JA) treatment using gene ontology (GO) terms (A) $2 \mathrm{~d}$ after JA treatment and (B) $60 \mathrm{~d}$ after JA treatment. Roots were treated with $10 \mu \mathrm{M}$ JA or water following harvest and incubated at $20^{\circ} \mathrm{C}$ and $90 \%$ relative humidity for up to $60 \mathrm{~d}$. 
Fugate et al., p. 36

Fig. 4. Effect of jasmonic acid (JA) on expression of defense-related unigenes with homology to three putative regulatory proteins and three pathogenesis-related (PR) proteins in the $60 \mathrm{~d}$ following treatment. Differential expression was determined for unigenes encoding a coiled-coil (CC)-nucleotide-binding site (NBS)-leucine-rich repeat (LRR) resistance protein (unigene 9115), two NBS-LRR resistance proteins (unigenes 10601 and 77250; 29351), a PR thaumatin family protein (unigene 81205), and two acidic chitinases (unigenes 71046; 53522, 66180, and 70896). Roots were treated with $10 \mu \mathrm{M}$ JA or water (control) following harvest and incubated at $20^{\circ} \mathrm{C}$ and $90 \%$ relative humidity for up to $60 \mathrm{~d}$. Differential expression was determined by qRT-PCR. Alterations in fold regulation less than $|2.0|$ were considered insignificant and are indicated by gray bars (Holstege et al., 1998).

Fig. 5. Effect of jasmonic acid (JA) on expression of defense-related unigenes with homology to four oxidase-encoding unigenes and two unigenes with prominent roles in secondary metabolite biosynthesis. Differential expression was determined for unigenes encoding three putative laccase proteins (unigenes $11281 ; 51666,67039$, and 68954; 78937), a peroxidase protein (unigenes 42562 and 66692), a cinnamate 4-hydroxylase (unigenes 30677 and 55958), and a salicylic acid carboxyl methyltransferase (unigene 29506). Roots were treated with $10 \mu \mathrm{M}$ JA or water (control) following harvest and incubated at $20{ }^{\circ} \mathrm{C}$ and $90 \%$ relative humidity for up to $60 \mathrm{~d}$. Differential expression was determined by qRT-PCR. Alterations in fold regulation less than |2.0| were considered insignificant and are indicated by gray bars (Holstege et al., 1998). 
Fugate et al., p. 37

Fig. 6. Effect of jasmonic acid on (A) peroxidase (POD) and (B) cinnamate 4-hydroxylase (C4H) activities. Roots were treated with $10 \mu \mathrm{M}$ JA or water (control) following harvest and incubated at $20^{\circ} \mathrm{C}$ and $90 \%$ relative humidity for up to $60 \mathrm{~d}$. Activities are expressed as $\mu$ mole product formed per g protein per minute. Data are the mean \pm SE of the mean, with $n=8$. 
Fig. 1

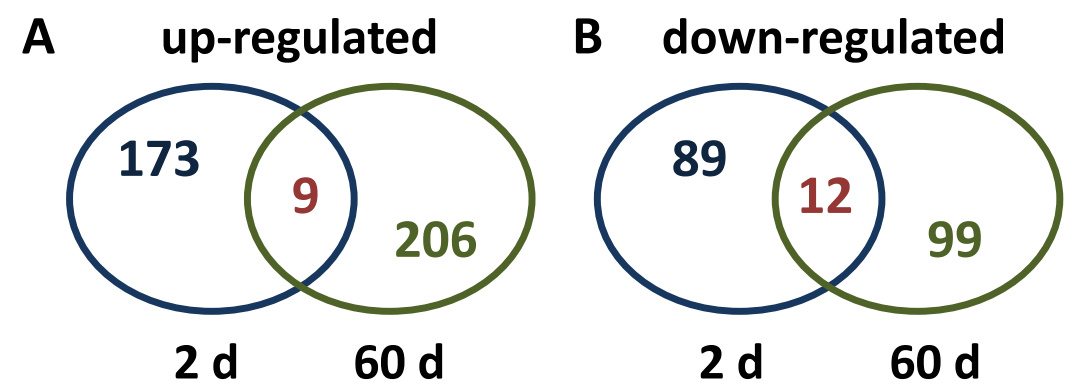


Fig. 2

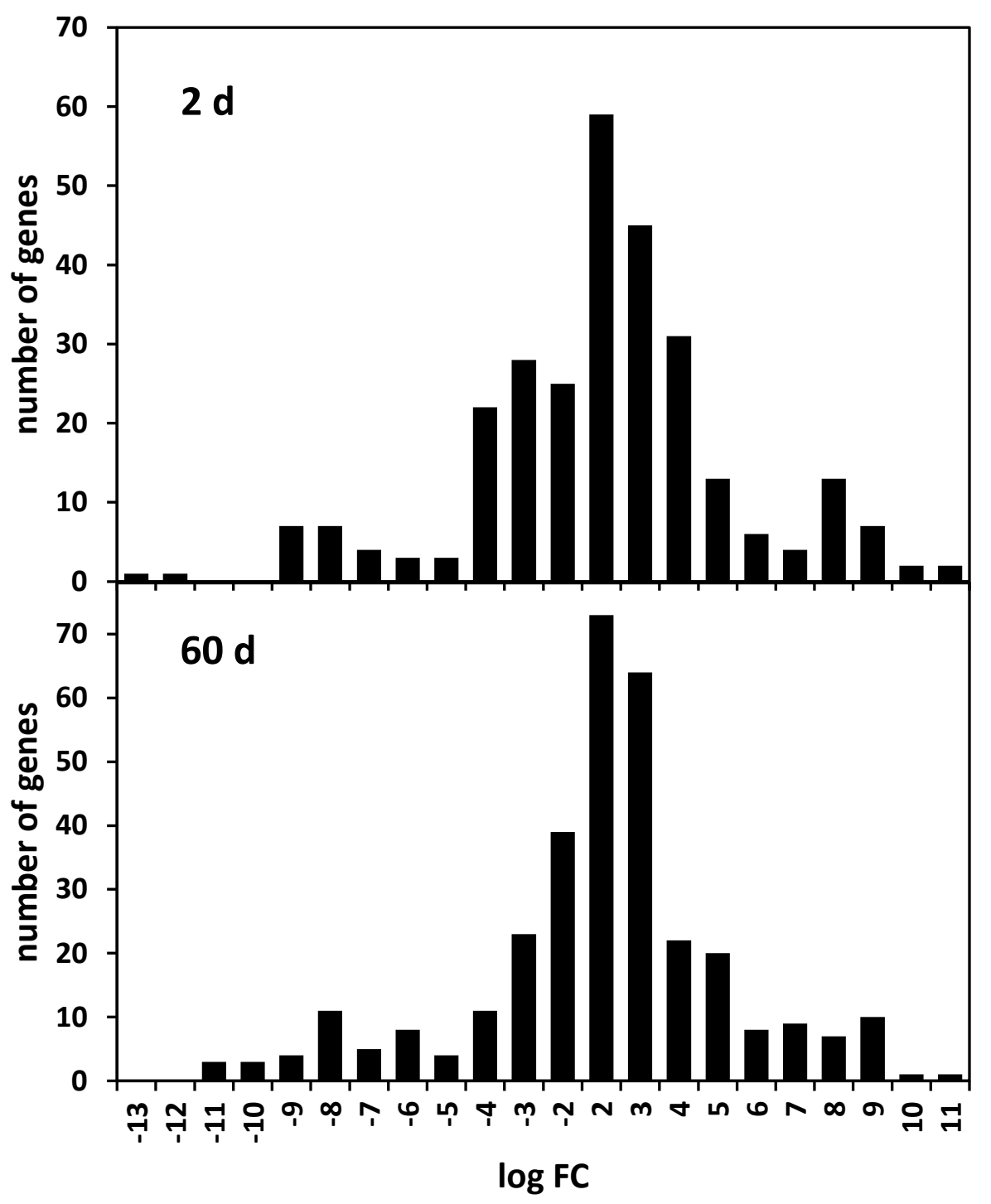


A

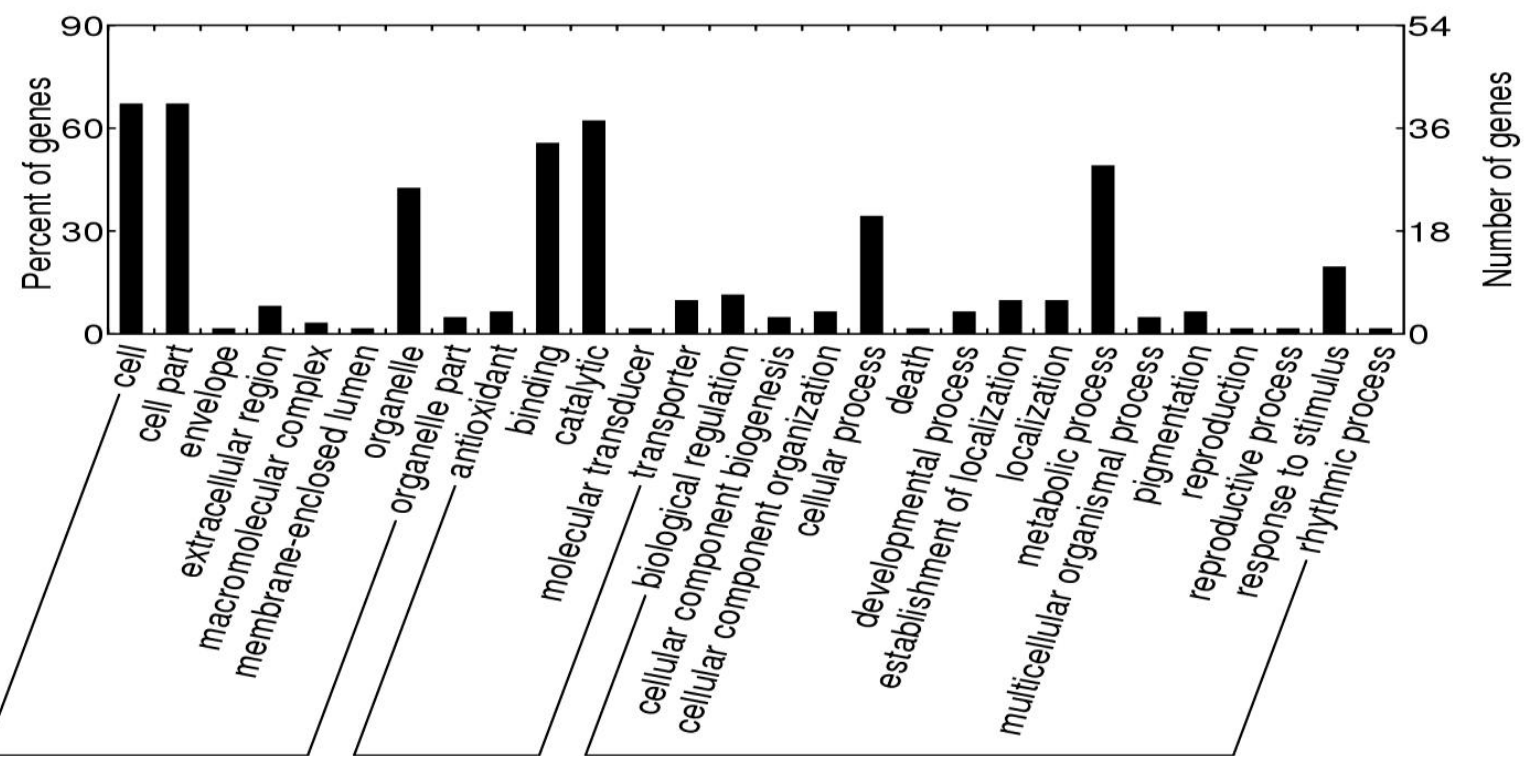

\section{Cell component Molecular function Biological process}

B

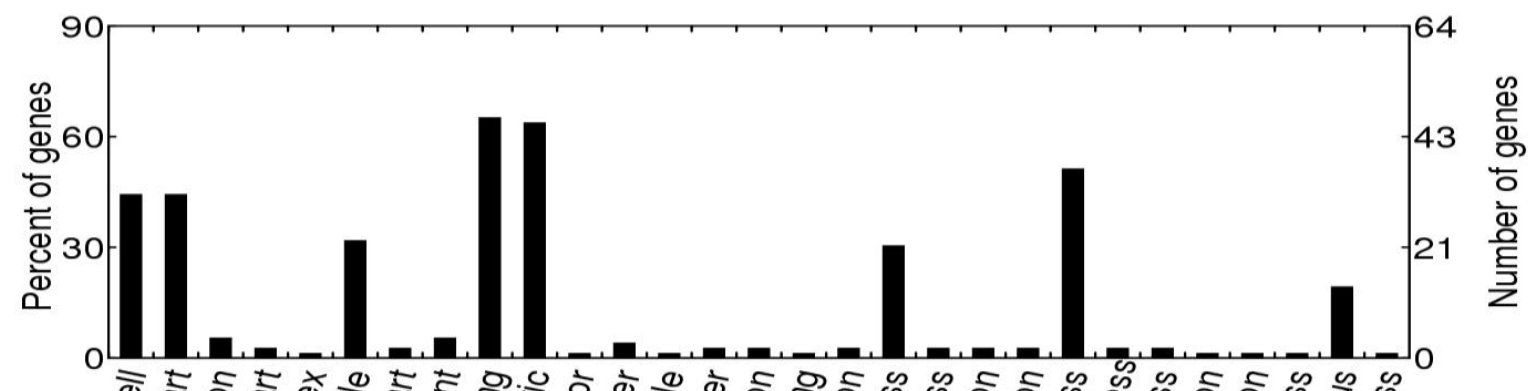

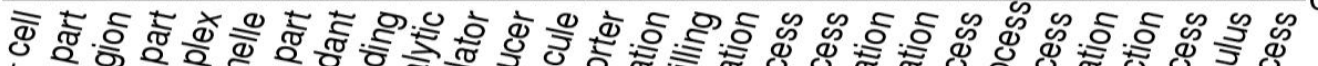

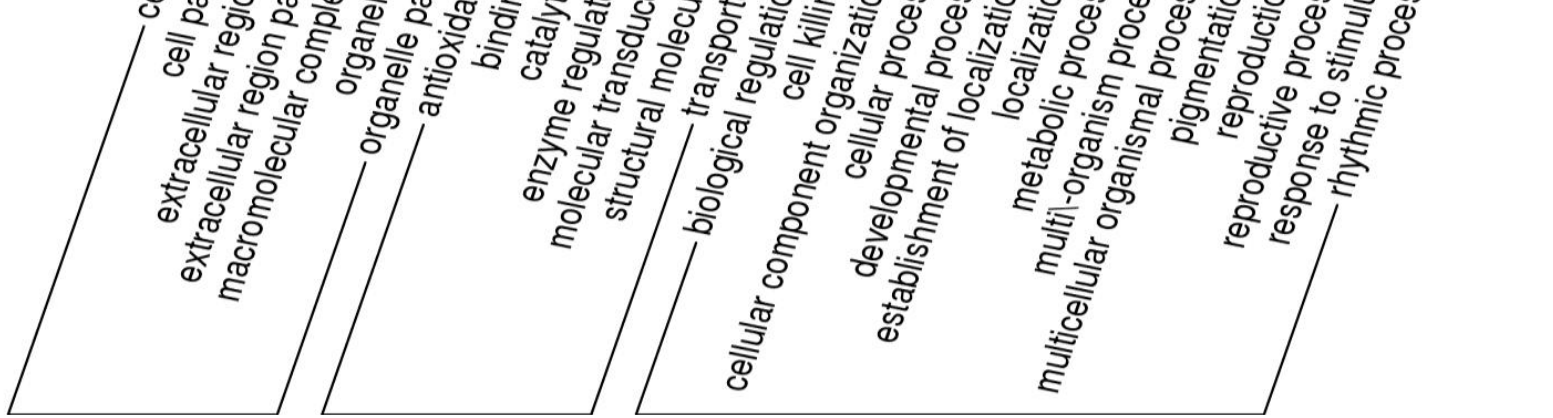

Cell component Molecular function Biological process 
Fig. 4
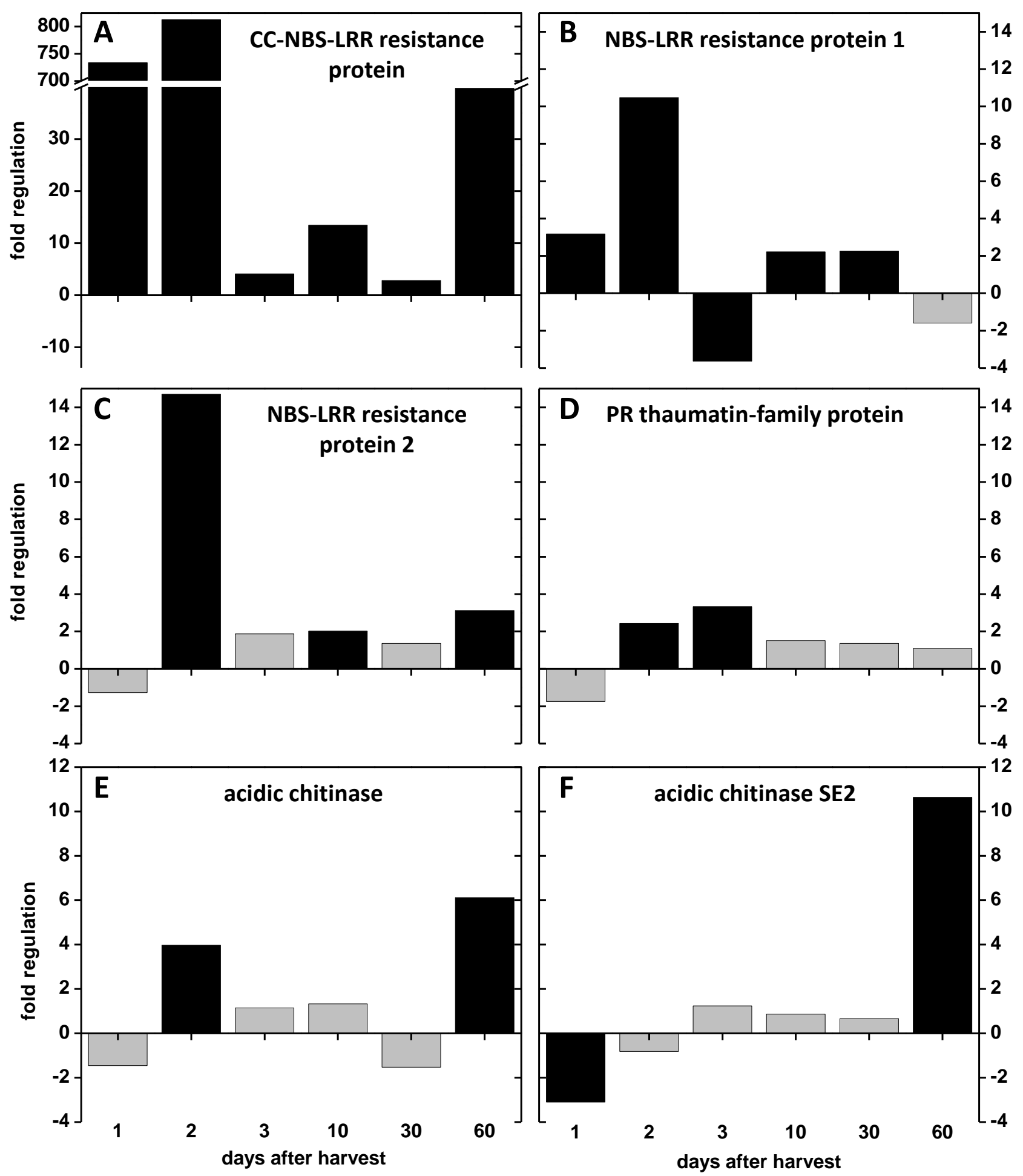
Fig. 5
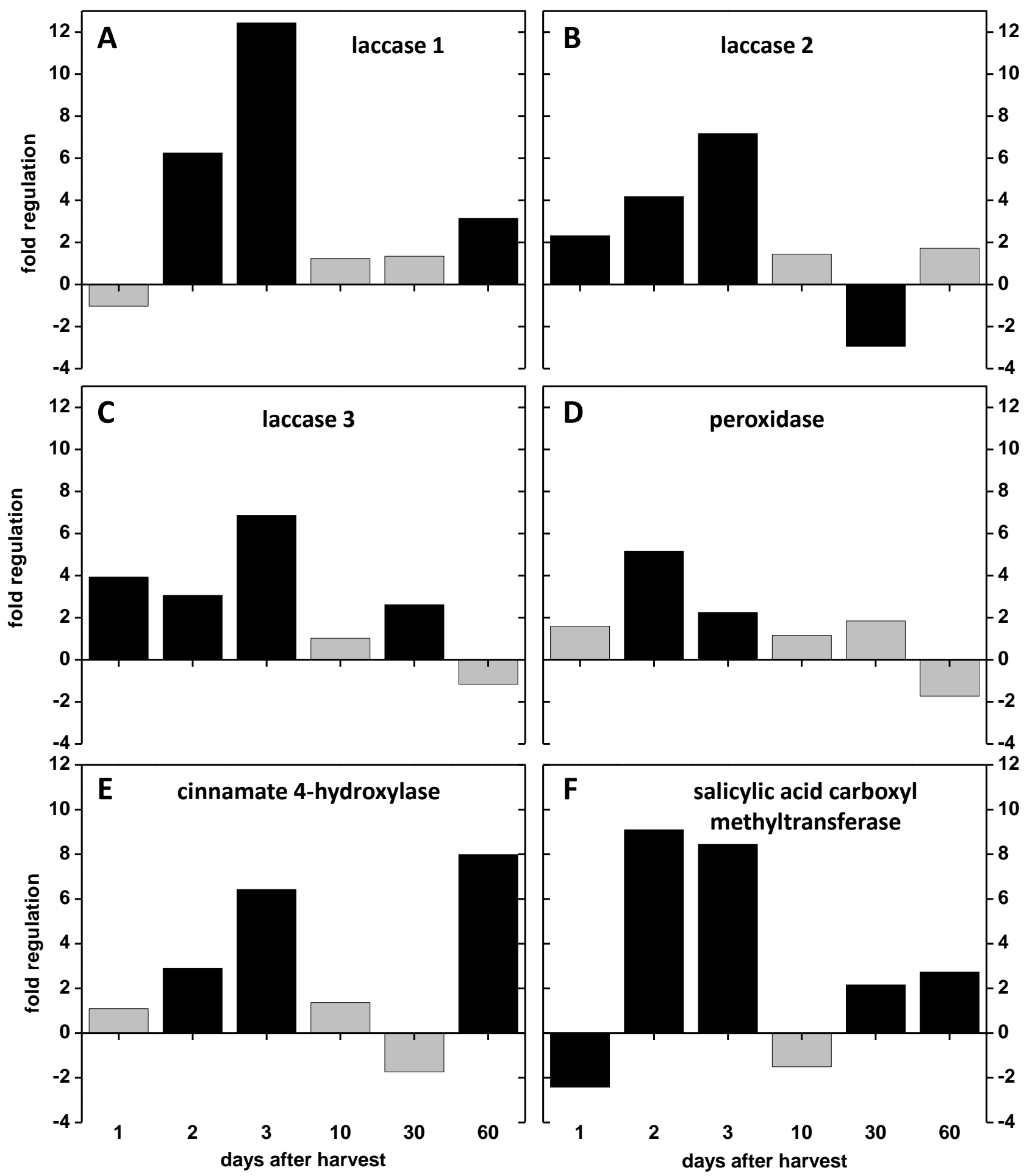
Fig. 6

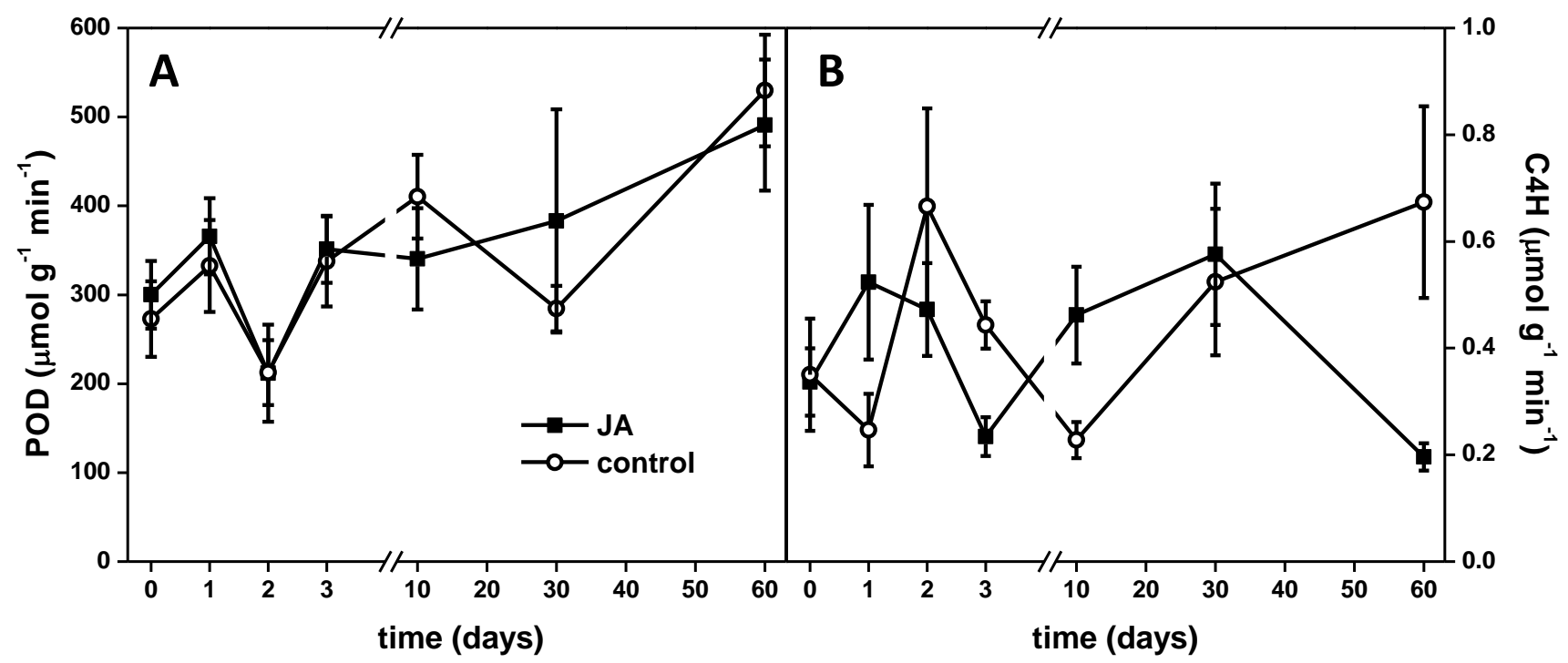




\section{Table 1}

Primer sequences used for qPCR analysis of select sugarbeet genes. Unigene numbers

correspond to the unigenes identified in a sugarbeet transcriptome (Fugate, 2013; Fugate et al.,

2014). Multiple unigene numbers are presented for unigenes that coalign to different portions

of the same gene as determined by alignment of unigenes to the sugarbeet genome (Dohm et

al., 2014).

\begin{tabular}{lccc}
\hline Gene & Accession/Unigene number & Forward primer & Reverse primer \\
\hline -actin & DQ866829 & GATTTGGCACCACACCTTCT & TCTTTCCCTGTTTGCCTTG \\
acidic chitinase & 71046 & CTGGATTCGGGGTAACCATA & ACGCTGCTAGCTAGGCTGAA \\
acidic chitinase SE2 & $53522,66180,70896$ & CATCAAAACATGCCAACAGG & CTGGACTGACCCCCAAGATA \\
CC-NBS-LRR resistance protein & 9115 & TGGGCTACTGGCTACTGCTT & GCTTGGATCATCTCCATGCT \\
cinnamate 4-hydroxylase & 30677,55958 & GGTTGGCTAACAACCCTGAA & CTCCTCCTTCCAACACCAAA \\
laccase I & 11281 & CCAAGCCACACCACTTACCT & CGTTTATGGAAGGGAGACGA \\
laccase II & $51666,67039,68954$ & AAGGACAGGGTGGTCAGATG & CCAAGTTTGGGCAAGATGAC \\
laccase III & 78937 & CCATCATATTTGGGGAGTGG & CAAACCTTTAGCTCCCATGC \\
NBS-LRR resistance protein 1 & 10601,77250 & GATTGGGAGAAGGCGTACAA & ATCAATCCCTCAGCAATCCA \\
NBS-LRR resistance protein 2 & 29351 & GGGTAAGAGAGTTGCCAAGC & TCCACAAGTGCAGAAGTCG \\
pathogenesis-related thaumatin family protein & 81205 & GCCGGTGTCTGTCTTAGTCC & CCACCTCCATCCTTGACTTG \\
peroxidase & 42562,66692 & CTGCTCAAGCAACCAAAACC & TAGGCGAGCAGGGACTTTAG \\
salicylic acid carboxyl methyltransferase & 29506 & GAGCTGTGGTTGAGCCCTTA & TTCGTCAGCCTCGACTTCTT \\
\hline
\end{tabular}




\section{Table 2}

Frequency of differentially expressed unigenes in sugarbeet roots 2 and $60 \mathrm{~d}$ after jasmonic acid (JA) treatment. Roots were treated with $10 \mu \mathrm{M}$ JA or water and stored at $20^{\circ} \mathrm{C}$ for 2 or $60 \mathrm{~d}$ after treatment. Differentially expressed unigenes were identified by RNA sequencing. Values in parentheses are the percentage of the total number of differentially expressed unigenes. Unigenes with no BLAST match were those that returned no matches from a BLASTx search of the gene sequence against the GenBank nr database. Unknown function denotes unigenes that matched a gene sequence within GenBank for a protein of unknown function.

\begin{tabular}{ccc}
\hline & $2 \mathrm{~d}$ & $60 \mathrm{~d}$ \\
\hline total number of unigenes & 283 & 326 \\
up-regulated (\%) & $182(64)$ & $215(66)$ \\
no BLAST match & $69(24)$ & $74(23)$ \\
BLAST match & $113(40)$ & $141(43)$ \\
unknown function & $10(4)$ & $15(5)$ \\
down-regulated (\%) & $101(36)$ & $111(34)$ \\
no BLAST match & $75(27)$ & $74(23)$ \\
BLAST match & $26(9)$ & $37(11)$ \\
unknown function & $9(3)$ & $10(3)$ \\
\hline
\end{tabular}




\title{
Table 3
}

\section{Kyoto Encyclopedia of Genes and Genomes (KEGG) pathways to which unigenes that were}

\author{
differentially expressed in sugarbeet roots $2 \mathrm{~d}$ after jasmonic acid (JA) treatment were assigned.
}

\author{
Roots were treated with $10 \mu \mathrm{M} \mathrm{JA}$ or water for $1 \mathrm{~h}$ and incubated for $2 \mathrm{~d}$ at $20^{\circ} \mathrm{C}$. Differential
}

expression of unigenes was determined by RNA sequencing.

\begin{tabular}{|c|c|c|}
\hline Pathway & KEGG ID & KEGG annotation (unigene number) \\
\hline \multirow[t]{12}{*}{ Metabolic pathways } & K00134 & glyceraldehyde 3-phosphate dehydrogenase (41959) \\
\hline & K00423 & L-ascorbate oxidase $(11281,29708,67039,68954,77135,78937)$ \\
\hline & K00430 & peroxidase $(34661,42562,66692)$ \\
\hline & K00487 & trans-cinnamate 4-monooxygenase (30677) \\
\hline & K00826 & branched-chain amino acid aminotransferase (29499) \\
\hline & K01051 & pectinesterase $(80875)$ \\
\hline & K01113 & phoD; alkaline phosphatase D (25607) \\
\hline & K01897 & long-chain acyl-CoA synthetase (30836) \\
\hline & K04120 & ent-copalyl diphosphate synthase (30930) \\
\hline & K05350 & beta-glucosidase (55314) \\
\hline & K08248 & mandelonitrile lyase (75893) \\
\hline & K09833 & $\begin{array}{l}\text { homogentisate phytyltransferase / homogentisate } \\
\text { geranylgeranyltransferase (71638) }\end{array}$ \\
\hline \multirow[t]{10}{*}{ Biosynthesis of secondary metabolites } & K00134 & glyceraldehyde 3-phosphate dehydrogenase (41959) \\
\hline & K00430 & peroxidase $(34661,42562,66692)$ \\
\hline & K00487 & trans-cinnamate 4-monooxygenase (30677) \\
\hline & K00826 & branched-chain amino acid aminotransferase (29499) \\
\hline & K01183 & chitinase (71046) \\
\hline & K04120 & ent-copalyl diphosphate synthase (30930) \\
\hline & K05350 & bglB; beta-glucosidase (55314) \\
\hline & K08248 & mandelonitrile lyase (75893) \\
\hline & K09833 & $\begin{array}{l}\text { homogentisate phytyltransferase / homogentisate } \\
\text { geranylgeranyltransferase ( } 71638)\end{array}$ \\
\hline & K11821 & desulfoglucosinolate sulfotransferase A/B/C (66725) \\
\hline \multirow[t]{3}{*}{ Plant-pathogen interaction } & K05391 & cyclic nucleotide gated channel, other eukaryote $(576,76243)$ \\
\hline & K13430 & serine/threonine-protein kinase PBS1 (14728) \\
\hline & K13457 & disease resistance protein $(6185,7601,10601,29351,77250)$ \\
\hline \multirow[t]{3}{*}{ Phenylpropanoid biosynthesis } & K00430 & peroxidase $(34661,42562,66692)$ \\
\hline & K00487 & trans-cinnamate 4-monooxygenase (30677) \\
\hline & K05350 & beta-glucosidase (55314) \\
\hline \multirow[t]{3}{*}{ Plant hormone signal transduction } & K13946 & auxin influx carrier $(16917,26919,78540)$ \\
\hline & K14492 & two-component response regulator ARR-A family (20004) \\
\hline & K14493 & gibberellin receptor GID1 (72228) \\
\hline \multirow[t]{2}{*}{ Phenylalanine metabolism } & K00430 & peroxidase $(34661,42562,66692)$ \\
\hline & K00487 & trans-cinnamate 4-monooxygenase (30677) \\
\hline \multirow[t]{2}{*}{ Starch and sucrose metabolism } & K01051 & pectinesterase $(80875)$ \\
\hline & K05350 & bg|B; beta-glucosidase (55314) \\
\hline \multirow[t]{2}{*}{ 2-Oxocarboxylic acid metabolism } & K00826 & branched-chain amino acid aminotransferase (29499) \\
\hline & K11821 & desulfoglucosinolate sulfotransferase $A / B / C$ (66725) \\
\hline \multirow[t]{2}{*}{ Ubiquinone and other terpenoid-quinone biosynthesis } & K00487 & trans-cinnamate 4-monooxygenase (30677) \\
\hline & K09833 & $\begin{array}{l}\text { homogentisate phytyltransferase / homogentisate } \\
\text { geranylgeranyltransferase ( } 71638 \text { ) }\end{array}$ \\
\hline \multirow[t]{2}{*}{ Cyanoamino acid metabolism } & K05350 & beta-glucosidase (55314) \\
\hline & K08248 & mandelonitrile lyase (75893) \\
\hline \multirow[t]{2}{*}{ Biosynthesis of amino acids } & K00134 & glyceraldehyde 3-phosphate dehydrogenase (41959) \\
\hline & K00826 & branched-chain amino acid aminotransferase (29499) \\
\hline \multirow[t]{2}{*}{$A B C$ transporters } & K05658 & ATP-binding cassette, subfamily B (MDR/TAP), member 1 (6688) \\
\hline & K05681 & $\begin{array}{l}\text { ATP-binding cassette, subfamily G (WHITE), member } 2 \text { (78801, } \\
81041 \text { ) }\end{array}$ \\
\hline Folate biosynthesis & K01113 & alkaline phosphatase $D(25607)$ \\
\hline
\end{tabular}


Tryptophan metabolism

Pentose and glucuronate interconversions

Carbon fixation in photosynthetic organisms

Pantothenate and CoA biosynthesis

Valine, leucine and isoleucine degradation

Other glycan degradation

Flavonoid biosynthesis

Pyruvate metabolism

Fatty acid degradation

Spliceosome

Valine, leucine and isoleucine biosynthesis

Metabolism of xenobiotics by cytochrome P450

Diterpenoid biosynthesis

Glutathione metabolism Fatty acid metabolism

Fatty acid metabolism

Glycolysis / Gluconeogenesis

Lysosome

Fatty acid biosynthesis

Stilbenoid, diarylheptanoid and gingerol biosynthesis

Degradation of aromatic compounds

Peroxisome

Ascorbate and aldarate metabolism

Glucosinolate biosynthesis

Carbon metabolism

Base excision repair

Amino sugar and nucleotide sugar metabolism

Aminobenzoate degradation

Two-component system
K11821 ST5A_B_C; desulfoglucosinolate sulfotransferase A/B/C (66725)

K01051 pectinesterase (80875)

K00134 glyceraldehyde 3-phosphate dehydrogenase (41959)

K00826 branched-chain amino acid aminotransferase (29499)

K00826 branched-chain amino acid aminotransferase (29499)

K01191 alpha-mannosidase (29022)

K00487 trans-cinnamate 4-monooxygenase (30677)

K00102 D-lactate dehydrogenase (cytochrome) (1282)

K01897 long-chain acyl-CoA synthetase (30836)

K12823 ATP-dependent RNA helicase DDX5/DBP2 (19671)

K00826 branched-chain amino acid aminotransferase (29499)

K00799 GST; glutathione S-transferase (25150)

K04120 ent-copalyl diphosphate synthase (30930)

K00799 glutathione S-transferase (25150)

K01897 long-chain acyl-CoA synthetase (30836)

K00134 glyceraldehyde 3-phosphate dehydrogenase (41959)

K13289 cathepsin A (carboxypeptidase C) $(25408,38313,52307,56439$, $61227,80067,80285$ )

K01897 long-chain acyl-CoA synthetase (30836)

K00487 trans-cinnamate 4-monooxygenase (30677)

K00487 trans-cinnamate 4-monooxygenase (30677)

K01897 long-chain acyl-CoA synthetase $(30836)$

K00423 L-ascorbate oxidase $(11281,29708,67039,68954,77135,78937)$

K11821 desulfoglucosinolate sulfotransferase A/B/C (66725)

K00134 glyceraldehyde 3-phosphate dehydrogenase (41959)

K01246 DNA-3-methyladenine glycosylase I (18548)

K01183 chitinase (71046)

K01113 alkaline phosphatase D (25607)

K01113 alkaline phosphatase D (25607) 


\title{
Table 4
}

\section{Kyoto Encyclopedia of Genes and Genomes (KEGG) pathways to which unigenes that were}

\author{
differentially expressed in sugarbeet roots $60 \mathrm{~d}$ after jasmonic acid (JA) treatment were
}

assigned. Roots were treated with $10 \mu \mathrm{M} \mathrm{JA}$ or water for $1 \mathrm{~h}$ and incubated for $60 \mathrm{~d}$ at $20^{\circ} \mathrm{C}$.

Differential expression of unigenes was determined by RNA sequencing.

\begin{tabular}{|c|c|c|}
\hline Pathway & KEGG ID & KEGG annotation (unigene number) \\
\hline \multirow[t]{13}{*}{ Metabolic pathways } & K00430 & peroxidase $(6736,51945,59365,67714)$ \\
\hline & K00487 & trans-cinnamate 4 -monooxygenase $(30677,55958,77129)$ \\
\hline & K00517 & E1.14.--- $(1078,77961,80332)$ \\
\hline & K00588 & caffeoyl-CoA O-methyltransferase (58834) \\
\hline & K00660 & chalcone synthase (25992) \\
\hline & K00815 & tyrosine aminotransferase (66299) \\
\hline & K01051 & pectinesterase (79221) \\
\hline & K01115 & phospholipase D1/2 $(19566,80130)$ \\
\hline & K01184 & polygalacturonase $(8462,26578)$ \\
\hline & K01859 & chalcone isomerase $(79381,81280)$ \\
\hline & K05280 & flavonoid 3'-monooxygenase $(42388,78883)$ \\
\hline & K05933 & aminocyclopropanecarboxylate oxidase (37058) \\
\hline & K13065 & shikimate O-hydroxycinnamoyltransferase (78279) \\
\hline \multirow[t]{12}{*}{ Biosynthesis of secondary metabolites } & K00430 & peroxidase $(6736,51945,59365,67714)$ \\
\hline & K00487 & trans-cinnamate 4 -monooxygenase $(30677,55958,77129)$ \\
\hline & K00517 & E1.14.--- $(1078,77961,80332)$ \\
\hline & K00588 & caffeoyl-CoA O-methyltransferase (58834) \\
\hline & K00660 & chalcone synthase (25992) \\
\hline & K00815 & tyrosine aminotransferase (66299) \\
\hline & K01183 & chitinase $(19460,19666,41811,53522,66180,70397,70653,70896)$ \\
\hline & K01859 & chalcone isomerase $(79381,81280)$ \\
\hline & K05280 & flavonoid 3'-monooxygenase $(42388,78883)$ \\
\hline & K05356 & $\begin{array}{l}\text { all-trans-nonaprenyl-diphosphate synthase }(16505,31995,37058 \text {, } \\
58710,76104)\end{array}$ \\
\hline & K05933 & aminocyclopropanecarboxylate oxidase (37058) \\
\hline & K13065 & shikimate O-hydroxycinnamoyltransferase (78279) \\
\hline \multirow[t]{6}{*}{ Flavonoid biosynthesis } & K00487 & trans-cinnamate 4-monooxygenase $(30677,55958,77129)$ \\
\hline & K00588 & caffeoyl-CoA O-methyltransferase (58834) \\
\hline & K00660 & chalcone synthase (25992) \\
\hline & K01859 & chalcone isomerase $(79381,81280)$ \\
\hline & K05280 & flavonoid 3'-monooxygenase $(42388,78883)$ \\
\hline & K13065 & shikimate O-hydroxycinnamoyltransferase (78279) \\
\hline \multirow[t]{5}{*}{ Plant-pathogen interaction } & K13420 & LRR receptor-like serine/threonine-protein kinase FLS2 (30081) \\
\hline & K13424 & WRKY transcription factor $33(27612,76071)$ \\
\hline & K13430 & serine/threonine-protein kinase PBS1 [EC:2.7.11.1] $(17858,63292)$ \\
\hline & K13449 & pathogenesis-related protein $1(18805)$ \\
\hline & K13457 & disease resistance protein RPM1 (10601) \\
\hline \multirow[t]{4}{*}{ Phenylalanine metabolism } & K00430 & peroxidase $(6736,51945,59365,67714)$ \\
\hline & K00487 & trans-cinnamate 4-monooxygenase $(30677,55958,77129)$ \\
\hline & K00588 & caffeoyl-CoA O-methyltransferase (58834) \\
\hline & K00815 & tyrosine aminotransferase (66299) \\
\hline \multirow[t]{4}{*}{ Stilbenoid, diarylheptanoid and gingerol biosynthesis } & K00487 & trans-cinnamate 4-monooxygenase $(30677,55958,77129)$ \\
\hline & K00517 & E1.14.--- $(1078,77961,80332)$ \\
\hline & K00588 & caffeoyl-CoA O-methyltransferase (58834) \\
\hline & K13065 & shikimate O-hydroxycinnamoyltransferase (78279) \\
\hline \multirow[t]{4}{*}{ Phenylpropanoid biosynthesis } & K00430 & E1.11.1.7; peroxidase $(6736,51945,59365,67714)$ \\
\hline & K00487 & trans-cinnamate 4-monooxygenase $(30677,55958,77129)$ \\
\hline & K00588 & caffeoyl-CoA O-methyltransferase (58834) \\
\hline & K13065 & shikimate O-hydroxycinnamoyltransferase (78279) \\
\hline Endocytosis & K01115 & phospholipase D1/2 $(19566,80130)$ \\
\hline
\end{tabular}




\section{Spliceosome}

Pentose and glucuronate interconversions

Starch and sucrose metabolism

Ubiquinone and other terpenoid-quinone biosynthesis

Plant hormone signal transduction

Circadian rhythm - plant

RNA transport

Glutathione metabolism

Flavone and flavonol biosynthesis

Cysteine and methionine metabolism

Ribosome

Tropane, piperidine and pyridine alkaloid biosynthesis Isoquinoline alkaloid biosynthesis

Apoptosis

cAMP signaling pathway

Metabolism of xenobiotics by cytochrome P450

Lysosome

MAPK signaling pathway

Degradation of aromatic compounds

Carbon metabolism

$A B C$ transporters

Benzoxazinoid biosynthesis

Phenylalanine, tyrosine and tryptophan biosynthesis Protein processing in endoplasmic reticulum

Toll-like receptor signaling pathway

Limonene and pinene degradation

Zeatin biosynthesis

mRNA surveillance pathway

Nitrogen metabolism

Aminobenzoate degradation

RNA degradation

Tyrosine metabolism

Glyoxylate and dicarboxylate metabolism

Ascorbate and aldarate metabolism

Amino sugar and nucleotide sugar metabolism

Cyanoamino acid metabolism

Ribosome biogenesis in eukaryotes

Biosynthesis of amino acids

Glycerophospholipid metabolism

Polycyclic aromatic hydrocarbon degradation

Ether lipid metabolism

Terpenoid backbone biosynthesis
K03283 heat shock 70kDa protein 1/8 (23724)

K12471 EPN; epsin (69978)

K03283 heat shock 70kDa protein 1/8 (23724)

K12811 ATP-dependent RNA helicase DDX46/PRP5 (21644)

K12878 THO complex subunit 1 (3502)

K01051 pectinesterase (79221)

K01184 polygalacturonase $(8462,26578)$

K01051 pectinesterase (79221)

K01184 polygalacturonase $(8462,26578)$

K00487 trans-cinnamate 4-monooxygenase $(30677,55958,77129)$

K00815 tyrosine aminotransferase (66299)

K13415 protein brassinosteroid insensitive 1 (70406)

K13449 pathogenesis-related protein 1 (18805)

K00660 chalcone synthase (25992)

K12135 zinc finger protein CONSTANS (20593)

K12878 THO complex subunit 1 (3502)

K14326 regulator of nonsense transcripts $1(29471,82057)$

K00434 L-ascorbate peroxidase (69822)

K00799 glutathione S-transferase $(6804,22942,79709)$

K05279 flavonol 3-O-methyltransferase (20294)

K05280 flavonoid 3'-monooxygenase $(42388,78883)$

K00815 tyrosine aminotransferase (66299)

K05933 aminocyclopropanecarboxylate oxidase (37058)

K02942 large subunit ribosomal protein LP1 (5192)

K02996 small subunit ribosomal protein S9 (30454)

K00815 tyrosine aminotransferase (66299)

K00815 tyrosine aminotransferase (66299)

K04733 interleukin-1 receptor-associated kinase 4 (759)

K01115 phospholipase D1/2 (19566, 80130,)

K00799 glutathione S-transferase $(6804,22942,79709)$

K13289 cathepsin A (carboxypeptidase C) (75121)

K03283 heat shock 70kDa protein 1/8 (23724)

K00487 trans-cinnamate 4-monooxygenase $(30677,55958,77129)$

K01455 formamidase $(32409,39535)$

K05666 ATP-binding cassette, subfamily C (CFTR/MRP), member 2 (16505)

K13229 4-dihydroxy-1,4-benzoxazin-3-one-glucoside dioxygenase (69313, 73809)

K00815 tyrosine aminotransferase (66299)

K03283 heat shock 70kDa protein 1/8 (23724)

K04733 interleukin-1 receptor-associated kinase 4 (759)

K00517 E1.14.-.- $(1078,77961,80332)$

K13495 cis-zeatin O-glucosyltransferase (67857)

K14326 regulator of nonsense transcripts $1(29471,82057)$

K01455 formamidase $(32409,39535)$

K00517 E1.14.--- $(1078,77961,80332)$

K12619 5'-3' exoribonuclease $2(1219,29814)$

K00815 tyrosine aminotransferase (66299)

K01455 formamidase $(32409,39535)$

K00434 L-ascorbate peroxidase (69822)

K01183 chitinase $(19460,19666,41811,53522,66180,70397,70653,70896)$

K01455 formamidase $(32409,39535)$

K12619 5'-3' exoribonuclease $2(1219,29814)$

K00815 tyrosine aminotransferase (66299)

K01115 phospholipase D1/2 $(19566,80130)$

K00517 E1.14.-.- $(1078,77961,80332)$

K01115 phospholipase D1/2 $(19566,80130)$

K05356 all-trans-nonaprenyl-diphosphate synthase $(31995,58710,76104)$ 


\section{Table 5}

Differentially expressed unigenes with putative roles in plant defense in sugarbeet roots $2 \mathrm{~d}$ after treatment with jasmonic acid (JA) or water. Freshly harvested roots were treated with $10 \mu \mathrm{M} \mathrm{JA}$ or water for $1 \mathrm{~h}$ and incubated for $2 \mathrm{~d}$ at $20^{\circ} \mathrm{C}$. Gene expression was determined by RNA sequencing. Differentially expressed genes were defined as those with an absolute value of the logarithm of the fold change in expression (logFC) $\geq 1$, a false detection rate (FDR) $\leq 0.001$, and were significantly altered in expression in both repetitions of the experiment. Raw number of RNA-sequencing reads are listed for both biological repetitions where $\mathrm{JA}_{1}$ and control $\mathrm{I}_{1}$ are the raw reads for $\mathrm{JA}$ and water-treated roots from the $1^{\text {st }}$ biological repetition, and $\mathrm{JA}_{2}$ and control $\mathrm{I}_{2}$ are the raw reads for $\mathrm{JA}$ and watertreated roots from the 2 nd biological repetition. Annotations were from a BLASTx search of unigene sequences against GenBank's nonredundant (nr) protein database. Annotations from a BLAST search against the sugarbeet genome are available (Table 3, in Oliveira et al., in press). Unigenes analyzed by quantitative RT-PCR are underlined.

\begin{tabular}{|c|c|c|c|c|c|c|c|c|}
\hline \multirow{2}{*}{ Unigene ID } & \multirow{2}{*}{$\log \mathrm{FC}$} & \multicolumn{4}{|c|}{ Reads } & \multirow{2}{*}{ E value } & \multirow{2}{*}{ Nr-annotation } & \multirow[b]{2}{*}{$\mathrm{Nr}-\mathrm{ID}$} \\
\hline & & $\mathrm{JA}_{1}$ & control $_{1}$ & $\mathrm{JA}_{2}$ & control $_{2}$ & & & \\
\hline 10601 & 8.3 & 1 & - & 35 & - & $9 E-25$ & NBS-LRR resistance protein [Populus trichocarpa] & gi|224096480|ref|XP_002334697.1| \\
\hline$\underline{9115}$ & 6.0 & 77 & 2 & 237 & 3 & $8 \mathrm{E}-6$ & CC-NBS-LRR resistance protein [Populus trichocarpa] & gi|224092698|ref|XP_002309702.1| \\
\hline$\underline{11281}$ & 4.7 & 5 & - & 76 & 3 & 0 & laccase [Liriodendron tulipifera] & gi|1621467|gb|AAB17194.1| \\
\hline$\underline{81205}$ & 4.5 & 2 & - & 45 & 2 & $2 \mathrm{E}-79$ & pathogenesis-related thaumatin family protein [Arabidopsis thaliana] & gi|15242552|ref|NP_198818.1| \\
\hline$\underline{42562}$ & 4.1 & 6 & 1 & 117 & 6 & $1 \mathrm{E}-24$ & peroxidase [Spinacia oleracea] & gi|2956705|emb|CAA76377.1| \\
\hline 65362 & 4.1 & 22 & 1 & 14 & 1 & $2 \mathrm{E}-6$ & retrotransposon protein, putative, unclassified [Oryza sativa Japonica Group] & gi|108707503|gb|ABF95298.1| \\
\hline 28653 & 3.8 & 3 & 2 & 69 & 3 & $5 E-57$ & NAC domain protein, IPR003441 [Populus trichocarpa] & gi|224136718|ref|XP_002322398.1| \\
\hline$\underline{71046}$ & 3.8 & 64 & 5 & 24 & 1 & $1 \mathrm{E}-30$ & acidic chitinase [Elaeagnus umbellata] & gi|3126963|gb|AAC16010.1| \\
\hline$\underline{66692}$ & 3.8 & 7 & 2 & 178 & 12 & $1 E-58$ & peroxidase [Spinacia oleracea] & gi|2956707|emb|CAA76376.1| \\
\hline$\underline{29506}$ & 3.6 & 11 & 2 & 27 & 1 & $2 \mathrm{E}-11$ & salicylic acid carboxyl methyltransferase [Mikania micrantha] & gi|227278441|gb|ACP20216.1| \\
\hline$\overline{51666}$ & 3.5 & 5 & 2 & 40 & 2 & $3 E-32$ & laccase 1a [Populus trichocarpa] & gi|224139024|ref|XP_002322961.1| \\
\hline$\underline{77250}$ & 3.4 & 56 & 7 & 113 & 9 & $9 \mathrm{E}-35$ & NBS-LRR resistance protein [Populus trichocarpa] & gi|224096480|ref|XP_002334697.1| \\
\hline$\underline{29351}$ & 3.2 & 101 & 17 & 200 & 16 & $1 \mathrm{E}-28$ & NBS-LRR resistance protein [Populus trichocarpa] & gi|224075299|ref|XP_002304589.1| \\
\hline 77135 & 3.2 & 5 & 1 & 32 & 3 & $1 \mathrm{E}-105$ & LAC11 (laccase 11); laccase [Arabidopsis thaliana] & gi|22326581|ref|NP_195946.2| \\
\hline$\underline{67039}$ & 3.0 & 25 & 9 & 160 & 15 & $4 \mathrm{E}-61$ & laccase 1a [Populus trichocarpa] & gi|224139024|ref|XP_002322961.1| \\
\hline 29708 & 3.0 & 4 & 1 & 43 & 5 & $1 \mathrm{E}-125$ & laccase 3 [Populus trichocarpa] & gi|224112579|ref|XP_002316233.1| \\
\hline$\underline{68954}$ & 2.9 & 11 & 6 & 90 & 8 & $6 \mathrm{E}-59$ & laccase 1a [Populus trichocarpa] & gi|224139024|ref|XP_002322961.1| \\
\hline$\underline{30677}$ & 2.6 & 19 & 3 & 44 & 7 & $3 E-75$ & cinnamate 4-hydroxylase [Mesembryanthemum crystallinum] & gi|4206116 |gb|AAD11427.1| \\
\hline 78937 & 2.6 & 21 & 9 & 85 & 8 & $1 \mathrm{E}-83$ & laccase [Liriodendron tulipifera] & gi|1621463|gb|AAB17192.1| \\
\hline 16917 & 2.6 & 31 & 14 & 112 & 9 & $7 \mathrm{E}-37$ & glucosyltransferase [Phytolacca americana] & gi|204022238|dbj|BAG71127.1| \\
\hline 80875 & 2.6 & 5 & 2 & 54 & 8 & $1 \mathrm{E}-120$ & pectinesterase family protein [Arabidopsis lyrata subsp. lyrata] & gi|297823481|ref|XP_002879623.1| \\
\hline 26919 & 2.5 & 34 & 25 & 242 & 24 & $6 \mathrm{E}-60$ & glucosyltransferase [Phytolacca americana] & gi|204022238|dbj|BAG71127.1| \\
\hline 55314 & 2.5 & 10 & 2 & 51 & 9 & $2 \mathrm{E}-41$ & beta-glucosidase [Arabidopsis lyrata subsp. lyrata] & gi|297830448|ref|XP_002883106.1| \\
\hline 25408 & 2.3 & 13 & 6 & 77 & 13 & $1 \mathrm{E}-99$ & wound-inducible carboxypeptidase [Solanum lycopersicum] & gi|7271957|gb|AAF44708.1|AF242849_1 \\
\hline 7601 & 2.1 & 67 & 13 & 70 & 19 & $1 \mathrm{E}-13$ & Os03g0849500 disease resistance RPP8-like protein [Oryza sativa Japonica & gi|115456593|ref|NP_001051897.1| \\
\hline
\end{tabular}


Group]

\begin{tabular}{|c|c|c|c|c|c|c|c|c|}
\hline 80285 & 2.0 & 14 & 13 & 128 & 24 & $1 \mathrm{E}-108$ & wound-inducible carboxypeptidase [Solanum lycopersicum] & gi|7271957|gb|AAF44708.1|AF242849_1 \\
\hline 22064 & 1.8 & 57 & 44 & 377 & 80 & $6 \mathrm{E}-23$ & ABC transporter family protein [Arabidopsis thaliana] & gi|18398110|ref|NP_564383.1| \\
\hline 67654 & 1.8 & 173 & 78 & 328 & 63 & $4 \mathrm{E}-08$ & proteinase inhibitor [Jatropha curcas] & gi|284433788|gb|ADB85100.1| \\
\hline 81041 & 1.6 & 157 & 142 & 969 & 226 & $1 \mathrm{E}-115$ & $A B C$ transporter family protein [Arabidopsis lyrata subsp. lyrata] & gi|297851608|ref|XP_002893685.1| \\
\hline 78196 & 1.6 & 644 & 297 & 490 & 66 & $3 \mathrm{E}-6$ & ribosome-inactivating protein [Beta vulgaris] & gi|99646716|emb|CAK22417.1| \\
\hline 22684 & -1.8 & 1 & 98 & 2 & 190 & $1 \mathrm{E}-108$ & DNA binding [Arabidopsis thaliana] & gi|145336703|ref|NP_175754.2| \\
\hline 30280 & -2.7 & 53 & 98 & - & 89 & $1 \mathrm{E}-82$ & NAC domain protein, IPR003441 [Populus trichocarpa] & gi|224104873|ref|XP_002313601.1| \\
\hline 27839 & -3.1 & 22 & 58 & 3 & 102 & $6 \mathrm{E}-32$ & retrotransposon protein [Beta vulgaris] & gi|121501699|gb|ABM55240.1| \\
\hline 28841 & -3.8 & 6 & 38 & 1 & 24 & $6 \mathrm{E}-43$ & retrotransposon protein [Beta vulgaris] & gi|121501699|gb|ABM55240.1| \\
\hline 69707 & -4.3 & 30 & 214 & - & 174 & $7 E-50$ & retrotransposon protein [Beta vulgaris] & gi|121501699|gb|ABM55240.1| \\
\hline 10646 & -4.4 & 5 & 61 & - & 37 & $1 \mathrm{E}-58$ & retrotransposon protein [Beta vulgaris] & gi|121501699|gb|ABM55240.1| \\
\hline 77351 & -6.5 & 8 & 107 & - & 66 & $6 \mathrm{E}-58$ & CTV.20 [Citrus trifoliata] & gi|24461860|gb|AAN62347.1|AF506028_14 \\
\hline 5228 & -7.8 & - & 16 & - & 10 & $5 E-20$ & retrotransposon protein [Beta vulgaris] & gi|121501699|gb|ABM55240.1| \\
\hline
\end{tabular}




\section{Table 6}

Differentially expressed unigenes with putative roles in plant defense in sugarbeet roots $60 \mathrm{~d}$ after treatment with jasmonic acid (JA) or water. Freshly harvested roots were treated with $10 \mu \mathrm{M} \mathrm{JA}$ or water for $1 \mathrm{~h}$ and incubated for $60 \mathrm{~d}$ at $20^{\circ} \mathrm{C}$. Gene expression was determined by RNA sequencing. Differentially expressed genes were defined as those with an absolute value of the logarithm (base 2 ) of the fold change in expression (logFC) $\geq 1$, a false detection rate (FDR) $\leq 0.001$, and were significantly altered in expression in both repetitions of the experiment. Raw number of RNA-sequencing reads are listed for both biological repetitions where $\mathrm{JA}_{1}$ and control ${ }_{1}$ are the raw reads for $\mathrm{JA}$ and water-treated roots from the $1^{\text {st }}$ biological repetition, and $\mathrm{JA}_{2}$ and control ${ }_{2}$ are the raw reads for $\mathrm{JA}$ and water-treated roots from the 2 nd biological repetition. Annotations were from a BLASTx search of unigene sequences against GenBank's nonredundant (nr) protein database. Annotations from a BLAST search against the sugarbeet genome are available (Table 4 in Oliveira et al., in press). Unigenes analyzed by quantitative RT-PCR are underlined.

\begin{tabular}{|c|c|c|c|c|c|c|c|c|}
\hline \multirow{2}{*}{ Unigene ID } & \multirow{2}{*}{$\log \mathrm{FC}$} & \multicolumn{4}{|c|}{ Reads } & \multirow{2}{*}{ E value } & \multirow{2}{*}{ Nr-annotation } & \multirow{2}{*}{$\mathrm{Nr}-\mathrm{ID}$} \\
\hline & & $\mathrm{JA}_{1}$ & control $_{1}$ & $\mathrm{JA}_{2}$ & control $_{2}$ & & & \\
\hline 9968 & 9.3 & 84 & - & 1 & - & $1 \mathrm{E}-17$ & retrotransposon protein [Cucumis melo subsp. melo] & gi|307135889|gb|ADN33754.1| \\
\hline 65993 & 7.1 & 2 & - & 16 & - & $2 \mathrm{E}-06$ & AP2/ERF domain-containing transcription factor [Populus trichocarpa] & gi|224083841|ref|XP_002307142.1| \\
\hline 70406 & 7.1 & 3 & - & 15 & - & $2 \mathrm{E}-06$ & Leucine-rich repeat, plant specific [Medicago truncatula] & gi|124360665|gb|ABN08654.1| \\
\hline$\underline{55958}$ & 5.1 & 2 & 1 & 68 & 1 & $6 \mathrm{E}-13$ & cinnamate 4-hydroxylase [Mesembryanthemum crystallinum] & gi|4206116|gb|AAD11427.1| \\
\hline$\overline{30677}$ & 4.7 & 4 & 2 & 96 & 2 & $1 \mathrm{E}-14$ & cinnamate 4-hydroxylase [Mesembryanthemum crystallinum] & gi|4206116|gb|AAD11427.1| \\
\hline 20294 & 4.3 & 8 & 3 & 89 & 2 & $1 \mathrm{E}-13$ & O-methyltransferase [Vitis vinifera] & gi|300077149|gb|ADJ66851.1| \\
\hline 235 & 4.1 & 108 & 44 & 949 & 20 & $2 \mathrm{E}-25$ & ribosome-inactivating protein [Beta vulgaris] & gi|99646720|emb|CAK22418.1| \\
\hline 65143 & 4.1 & 125 & 72 & 1237 & 13 & $1 \mathrm{E}-25$ & ribosome-inactivating protein [Beta vulgaris] & gi|99646720|emb|CAK22418.1| \\
\hline 50108 & 3.5 & 6 & 4 & 39 & - & $1 \mathrm{E}-07$ & glycine-rich protein [Arabidopsis thaliana] & gi|18397934|ref|NP_565380.1| \\
\hline 79709 & 3.5 & 20 & 7 & 55 & - & $7 \mathrm{E}-10$ & glutathione S-transferase [Salicornia brachiata] & gi|124507403|gb|ABN13680.1| \\
\hline 77961 & 3.5 & 10 & 9 & 137 & 5 & $4 \mathrm{E}-13$ & cytochrome P450 [Populus trichocarpa] & gi|224063931|ref|XP_002301307.1| \\
\hline 20462 & 3.3 & 25 & 5 & 52 & 3 & $1 \mathrm{E}-09$ & pathogenesis-related protein 10a [Rheum australe] & gi|197312889|gb|ACH63225.1| \\
\hline 67367 & 3.3 & 66 & 10 & 36 & 1 & 1.E-10 & peroxidase 4 & gi|223635590|sp|A7NY33.1|PER4_VITVI \\
\hline 74869 & 3.2 & 12 & 6 & 40 & - & $2 \mathrm{E}-07$ & oxalate oxidase-like germin 171 [Beta vulgaris] & gi|11496133|gb|AAG36666.1| \\
\hline 42008 & 2.9 & 10 & 4 & 40 & 3 & $9 \mathrm{E}-07$ & pectinesterase family protein [Arabidopsis thaliana] & gi|15225308|ref|NP_180212.1| \\
\hline 51945 & 2.9 & 11 & 6 & 66 & 5 & $3 \mathrm{E}-08$ & peroxidase [Populus trichocarpa] & gi|225626263|gb|ACN97181.1| \\
\hline 29055 & 2.9 & 4 & 1 & 38 & 5 & $4 \mathrm{E}-06$ & CC-NBS-LRR resistance protein [Populus trichocarpa] & gi|224102623|ref|XP_002334156.1| \\
\hline 75464 & 2.8 & 640 & 132 & 288 & 11 & $5 \mathrm{E}-14$ & blight-associated protein P12 [Citrus trifoliata] & gi|160690672|gb|ABX46166.1| \\
\hline 69313 & 2.7 & 31 & 14 & 111 & 9 & $1 \mathrm{E}-09$ & desacetoxyvindoline 4-hydroxylase [Catharanthus roseus] & gi|1916643|gb|AAC49826.1| \\
\hline 80014 & 2.7 & 397 & 307 & 1596 & 23 & $4 \mathrm{E}-14$ & glucan endo-1,3-beta-D-glucosidase [Beta vulgaris subsp. vulgaris] & gi|4584556|emb|CAA53545.1| \\
\hline 77564 & 2.7 & 25 & 3 & 30 & 6 & $2 \mathrm{E}-06$ & Os01g0957100 [Oryza sativa Japonica Group] & gi|115442331|ref|NP_001045445.1| \\
\hline 19460 & 2.6 & 34 & 11 & 54 & 4 & $8 \mathrm{E}-08$ & chitinase-B, PLC-B [Phytolacca americana=pokeweed, leaves, Peptide, 274 aa] & gi|998516|gb|AAB34670.1| \\
\hline 48415 & 2.6 & 398 & 180 & 986 & 62 & $3 \mathrm{E}-13$ & pathogenesis-related protein [Tamarix hispida] & gi|217331222|gb|ACK38253.1| \\
\hline 66442 & 2.6 & 121 & 108 & 506 & 4 & $3 \mathrm{E}-12$ & beta-1,3-glucanase [Vitis riparia] & gi|37992763|gb|AAR06588.1| \\
\hline 13125 & 2.5 & 122 & 40 & 91 & - & $1 \mathrm{E}-09$ & Protein kinase; Type I EGF [Medicago truncatula] & gi|87162753|gb|ABD28548.1| \\
\hline$\underline{53522}$ & 2.5 & 310 & 113 & 392 & 20 & $1 \mathrm{E}-11$ & acidic endochitinase SE2 [Beta vulgaris] & gi|544000|sp|P36910.1|CHIE_BETVU \\
\hline 63292 & 2.5 & 21 & 13 & 53 & 1 & $8 \mathrm{E}-07$ & kinase family protein [Arabidopsis lyrata subsp. lyrata] & gi|297814900|ref|XP_002875333.1| \\
\hline 59365 & 2.5 & 9 & 6 & 69 & 9 & $6 \mathrm{E}-07$ & peroxidase [Mirabilis jalapa] & gi|46949194|gb|AAT07453.1| \\
\hline
\end{tabular}




\begin{tabular}{|c|c|c|c|c|c|c|c|c|}
\hline 66180 & 2.4 & 263 & 92 & 333 & 28 & $8 \mathrm{E}-11$ & acidic endochitinase SE2 [Beta vulgaris] & gi|544000|sp|P36910.1|CHIE_BETVU \\
\hline 8943 & 2.4 & 51 & 26 & 81 & 1 & $6 \mathrm{E}-08$ & protein kinase; peptidoglycan-binding LysM [Medicago truncatula] & gi|87162779|gb|ABD28574.1| \\
\hline 76071 & 2.3 & 81 & 23 & 74 & 9 & $3 \mathrm{E}-08$ & WRKY50; transcription factor [Arabidopsis thaliana] & gi|22327079|ref|NP_197989.2| \\
\hline 22942 & 2.3 & 57 & 28 & 102 & 6 & $4 \mathrm{E}-08$ & glutathione S-transferase; AltName: Full=GST class-phi [Silene vulgaris] & gi|417093|sp|Q04522.3|GSTF_SILCU \\
\hline 81280 & 2.3 & 130 & 75 & 265 & 12 & $2 \mathrm{E}-09$ & chalcone--flavonone isomerase; Short=Chalcone isomerase [Camellia sinensis] & gi|122233481|sp|Q45QI7.2|CFI_CAMSI \\
\hline 11500 & 2.2 & 14 & 9 & 151 & 29 & $1 \mathrm{E}-07$ & retrotransposon protein [Beta vulgaris] & gi|121501699|gb|ABM55240.1| \\
\hline 27612 & 2.2 & 105 & 29 & 23 & - & $4 \mathrm{E}-07$ & WRKY transcription factor [Artemisia annua] & gi|298108803|gb|ADI56655.1| \\
\hline 62435 & 2.2 & 428 & 239 & 667 & 18 & $7 \mathrm{E}-10$ & thaumatin-like protein [Mirabilis jalapa] & gi|46949200|gb|AAT07456.1| \\
\hline 72126 & 2.1 & 700 & 359 & 1029 & 62 & $1 \mathrm{E}-09$ & osmotin-like protein [Atriplex nummularia] & gi|166940|gb|AAA32908.1| \\
\hline 80552 & 2.1 & 112 & 63 & 719 & 141 & $2 \mathrm{E}-09$ & retrotransposon protein [Beta vulgaris] & gi|121501699|gb|ABM55240.1| \\
\hline 25992 & 2.1 & 59 & 33 & 160 & 21 & $1 \mathrm{E}-07$ & PKS, homology to chalcone synthase [Fallopia multiflora] & gi|300885273|gb|ADK45325.1| \\
\hline 31086 & 2.0 & 175 & 110 & 312 & 15 & $2 \mathrm{E}-08$ & Chain A, allergenic and antifungal banana fruit thaumatin-like protein At $1.7 \mathrm{a}$ & gi $|88191901| p d b|1 Z 3 Q| A$ \\
\hline 79221 & 2.0 & 53 & 32 & 122 & 13 & $5 \mathrm{E}-07$ & pectinesterase; pectinesterase inhibitor [Medicago truncatula] & gi|124360335|gb|ABN08348.1| \\
\hline 41811 & 2.0 & 50 & 27 & 71 & 5 & $3 \mathrm{E}-06$ & chitinase-B, PLC-B [Phytolacca americana=pokeweed, leaves, Peptide, 274 aa] & gi|998516|gb|AAB34670.1| \\
\hline 79381 & 2.0 & 115 & 76 & 227 & 17 & $1 \mathrm{E}-07$ & chalcone isomerase [Garcinia mangostana] & gi|222478417|gb|ACM62743.1| \\
\hline 24889 & 1.9 & 336 & 201 & 883 & 150 & $6 \mathrm{E}-08$ & phenylpropanoid:glucosyltransferase 1 [Nicotiana tabacum] & gi|13492674|gb|AAK28303.1|AF346431_1 \\
\hline 1078 & 1.8 & 246 & 140 & 353 & 45 & $6 \mathrm{E}-07$ & CYP81B2v1, homology to cytochrome P450 [Nicotiana tabacum] & gi|85068596|gb|ABC69378.1| \\
\hline$\underline{70896}$ & 1.8 & 446 & 195 & 464 & 88 & $4 \mathrm{E}-07$ & acidic endochitinase SE2; Flags: Precursor [Beta vulgaris] & gi|544000|sp|P36910.1|CHIE_BETVU \\
\hline 6804 & 1.7 & 172 & 132 & 363 & 39 & $1 \mathrm{E}-06$ & glutathione S-transferase class-phi [Silene vulgaris] & gi|417093|sp|Q04522.3|GSTF_SILCU \\
\hline 80332 & 1.7 & 308 & 205 & 544 & 71 & $1 \mathrm{E}-06$ & cytochrome P450 [Populus trichocarpa] & gi|224067244|ref|XP_002302427.1| \\
\hline 58834 & 1.6 & 272 & 193 & 434 & 47 & $3 E-06$ & anthocyanin-O-methyltransferase [Vitis vinifera] & gi|226374634|gb|ACO52469.1| \\
\hline 69822 & -2.5 & 1 & 201 & 2 & 47 & $5 \mathrm{E}-43$ & ascorbate peroxidase [Citrus maxima] & gi|221327587|gb|ACM17463.1| \\
\hline 30081 & -2.5 & 38 & 224 & 1 & 63 & $1 \mathrm{E}-129$ & leucine-rich repeat receptor-like protein kinase [Arabidopsis thaliana] & gi|224589491|gb|ACN59279.1| \\
\hline 22684 & -2.8 & 13 & 28 & 37 & 271 & $1 \mathrm{E}-108$ & DNA binding [Arabidopsis thaliana] & gi|145336703|ref|NP_175754.2| \\
\hline 77351 & -6.2 & 9 & 17 & 11 & 102 & $6 \mathrm{E}-58$ & CTV.20 [Citrus trifoliata] & gi|24461860|gb|AAN62347.1|AF506028_14 \\
\hline
\end{tabular}

